\title{
Mathematical Modeling to Estimate the Reproductive Number and the Outbreak Size of COVID-19: The case of India and the World
}

Durgesh Nandini Sinha ( $\nabla$ durgesh.sinha@temple.edu )

Temple University https://orcid.org/0000-0001-7749-3710

\section{Research Article}

Keywords: India Populations, World populations, COVID-19, Peak prediction, Reproduction number, SEIAQIm models

Posted Date: May 4th, 2020

DOI: https://doi.org/10.21203/rs.3.rs-26261/v1

License: (c) (i) This work is licensed under a Creative Commons Attribution 4.0 International License.

Read Full License 


\title{
Title: Mathematical Modeling to Estimate the Reproductive Number and the Outbreak Size of COVID-19: The case of India and the World.
}

\author{
Durgesh Nandini Sinha \\ Durgesh N Sinha (Adjunct Assistant Professor, Temple University, Philadelphia/ Strayer University (online)/Rowan College at Burlington \\ County, New Jersey/ Community College of Philadelphia/ Mercer County Community College, New Jersey) \\ Corresponding author: Durgesh N Sinha ( durgesh.sinha@temple.edu)
}

\begin{abstract}
:
Coronavirus disease (COVID-19) has become a global pandemic with more than 218,000 deaths in 211 different countries around the world. Severe acute respiratory syndrome coronavirus 2 (SARS-CoV-2) is the virus responsible for this deadliest disease. This paper describes a mathematical model for India, a country with the second highest population in the world with an extremely high population density of about 464 people per $\mathrm{km}^{2}$. This disease has multiphasic actions and reaction mode and our model SEIAQIm is based on six compartmental groups in the form of susceptible, exposed, infectious, asymptomatic, quarantine, and recovered immune factions. Latin Hypercube Sampling Partial Rank Correlation Coefficient method was used for the data analysis and model fitting. According to our model, India would reach its basic reproduction number $\mathrm{R} 0=0.97$ on May 14, 2020 with a total number of 73,800 estimated cases. Further, this study also equates the world's situation using the same model system and predicts by May 7, 2020 with a total number of 3,772,000 estimated confirmed cases. Moreover, the current mathematical model highlights the importance of social distancing as an effective method of containing spread of COVID-19.
\end{abstract}

\section{Key words: India, World populations, COVID-19, Peak prediction, Reproduction number, SEIAQIm models}

\section{Introduction}

The world is radically being altered with rapidly changing socioeconomic dynamics due to novel coronavirus pandemic. Currently 3.1 million people have been infected worldwide with more than 218,000 deaths $[1,3]$. India being the second most populous country in the world [4] with a very high population density was always at a very high risk. The epidemic may have struck India later than many other countries. India currently has more than 31,000 reported cases with more than 1000 deaths as of April 29, $2020[1,5]$. Lockdown and social distancing are the current mantra in the absence of a vaccine [6]. India announced a nationwide lockdown on March 25, 2020 to contain the spread of COVID-19. With a vast majority of infected people not showing any symptoms (asymptomatic) and a limited detection technology during the early stages, mathematical modeling of COVID-19 is far more challenging [6,7]. To help appreciate the possible dynamics of COVID-19 in India and the world as well as ways to contain it, this paper describes a mathematical model which relies on SEIAQIm (Susceptible, 
Exposed, Infectious, Asymptomatic, Quarantine, and Recovered Immune) compartmental model that is used by D. Sinha et al [8] to predict COVID-19 outbreak of the US population.

\subsection{Methods}

\section{Data Sources}

To estimate the early dynamics of COVID-19 transmission in India and world populations, we fitted a stochastic transmission dynamic model. The data from WHO, and Worldometer from February 11, 2020 to April 28, 2020 was used for this purpose $[1,2]$.

\section{2: Procedures}

In this model, individuals were divided into following six classes: susceptible, exposed (but not yet infectious), symptomatic infectious, asymptomatic infectious (individuals who do not show symptoms or directly recovered with immunity), quarantined (confirmed and isolated as infectious from both symptomatic and asymptomatic classes), and immuned class (recovered population that developed Immunity). The model accounted for delays in symptom onset and reporting by including compartments to reflect transition between reporting states and disease states. The incubation period used is from 2 to 14 days. The delay in hospitalization from confirmed cases, depending on severity, used is one day. Death rate is considered for both types of individuals those who died at hospital and others who died at home or in an isolation place. The death in hospitalization and treatment at home (isolation place) is $3.4 \%$ of confirmed cases.

\section{3: Model Formation and parameter classifications}

We divided the human population into four classes, SEIR

(Susceptible-Exposed-Infected-Recovered), and the bat population into three classes, $S_{b} E_{b} I_{b}$ (Susceptible-Exposed-Infected). Schematic flow of this model is shown in figure 2 and the state variables and associated parameters of this model are given in Table 1.



Figure 1. 
$S(t)$ : Susceptible humans in time $\mathrm{t}$

$E(t)$ : Exposed humans in time $\mathrm{t}$

$I(t)$ : Infectious humans in time $\mathrm{t}$

$\operatorname{Im}(t)$ : Recovered humans with Immunity in time $\mathrm{t}$

$A(t)$ : Asymptomatic infectious human in time $\mathrm{t}$

$Q(t)$ : Quarantine human in time

$N(t)$ : Total human population in time $\mathrm{t}$

$B$ : Birth rate of humans

$\beta i$ : Infectivity rate of COVID-19 from Symptomatic infectious class

$\beta_{A}$ : Infectivity rate of COVID-19 from Asymptomatic population class

$\beta_{\Theta}$ : Infectivity rate of COVID-19 from Quarantine population class

$\eta$ : Rate of transition from exposed to infected humans

$\alpha$ : Rate of transition from Quarantine to recovered humans

$\sigma:$ Rate of Immune humans from COVID-19

$\mathrm{Y}$ : Rate of transition from Infected class to Quarantine class

$\xi$ : Rate of transition from exposed to Asymptomatic infected class

$\lambda$ : Rate of transition from Asymptomatic class to Quarantine class

$\Theta$ : Rate of transition from Asymptomatic class to Recovered class with Immunity

$\mu$ : Natural death rate of humans

$\delta$ : Death rate of humans due to COVID-19

Our model contains six classes of human population: $S, E, I, A, Q$, and $I_{M}$. The $S$ class is the susceptible class of individuals that are able to be infected by COVID-19. They can be exposed to the virus from both infected, $I$, and asymptomatic people, $A$, that are not in quarantine. Both $I$ and $A$ can be tested for the virus and put into quarantine, $Q$, if tested positive. People in quarantine are still able to infect others around them, which gives the virus another transmission route through $\beta_{\theta}$. Those in quarantine would remain there for the suggested 3 to 6 weeks [1], before moving to the recovered class with immunity against COVID-19, $I_{M}$.

\subsection{Model Equations for humans population}

Based on the flow of transmission of COVID-19 in the human population as depicted in figure 1, we have the following system of equations:

$$
\begin{gathered}
\frac{d S}{d t}=B N-\beta i S I-\beta_{A} S A-\beta_{\mathrm{e}} S Q-\mu S \\
\frac{d E}{d t}=\beta i S I+\beta_{A} S A+\beta_{\mathrm{e}} S Q-(\mu+\eta+\xi+\sigma) E \\
\frac{d A}{d t}=\xi E-(\lambda+\theta+\mu) A \\
\frac{d I}{d t}=\eta E-(\mu+\gamma) I
\end{gathered}
$$




$$
\begin{aligned}
& \frac{d Q}{d t}=\gamma I+\lambda A-(\mu+\delta+\alpha) Q \\
& \frac{d I m}{d t}=\alpha Q+\theta A+\sigma E-\mu I m
\end{aligned}
$$

And

$$
N(t)=S(t)+E(t)+A(t)+I(t)+\operatorname{Im}(t)
$$

(2)

All our parameters are positive or non-negative, therefore all parameters must remain positive or non-negative for initial conditions for $\mathrm{t} \geq 0$.

From our model we have

$$
\frac{d N}{d t}=B-\mu N-\delta Q \leq B-\mu N
$$

The closed set $D=\left\{(S, E, A, I, Q, I m) \in R+{ }^{6} ; N \leq \frac{B}{\mu}\right\}$ is a feasible region for the graph.

\section{5: Stability of the Model}

In this section, we find the basic reproduction number and stability of the model. We proved that our model is locally and globally stable for both diseases-free-equilibrium and endemic equilibrium points.

Since all of our model parameters are positive or non-negative, it is important to show that all state variables remain positive or non-negative for all positive initial conditions for $t \geq 0$. From our model equation we have already established stability and have gone into further detail in other scientific works.

\subsection{Basic Reproduction number}

For any epidemic model, the basic reproduction number is the average number of secondary infectious cases produced by a single infection in the total susceptible population.

The basic reproduction number is calculated by $R_{0}=\mathscr{L}\left(F V^{-1}\right)$, where $\mathscr{L}$ is the spectral radius of the matrix $F V^{-1}$, and $F \& V$ are the matrices of new infection terms and the remaining transmission terms respectively.

By solving equation (1) and (2), we get $F$ and $V$ of the human population as given below:

$\left[\begin{array}{cccc}0 & \beta_{A} & \beta_{I} & \beta_{Q} \\ 0 & 0 & 0 & 0 \\ 0 & 0 & 0 & 0\end{array}\right]$



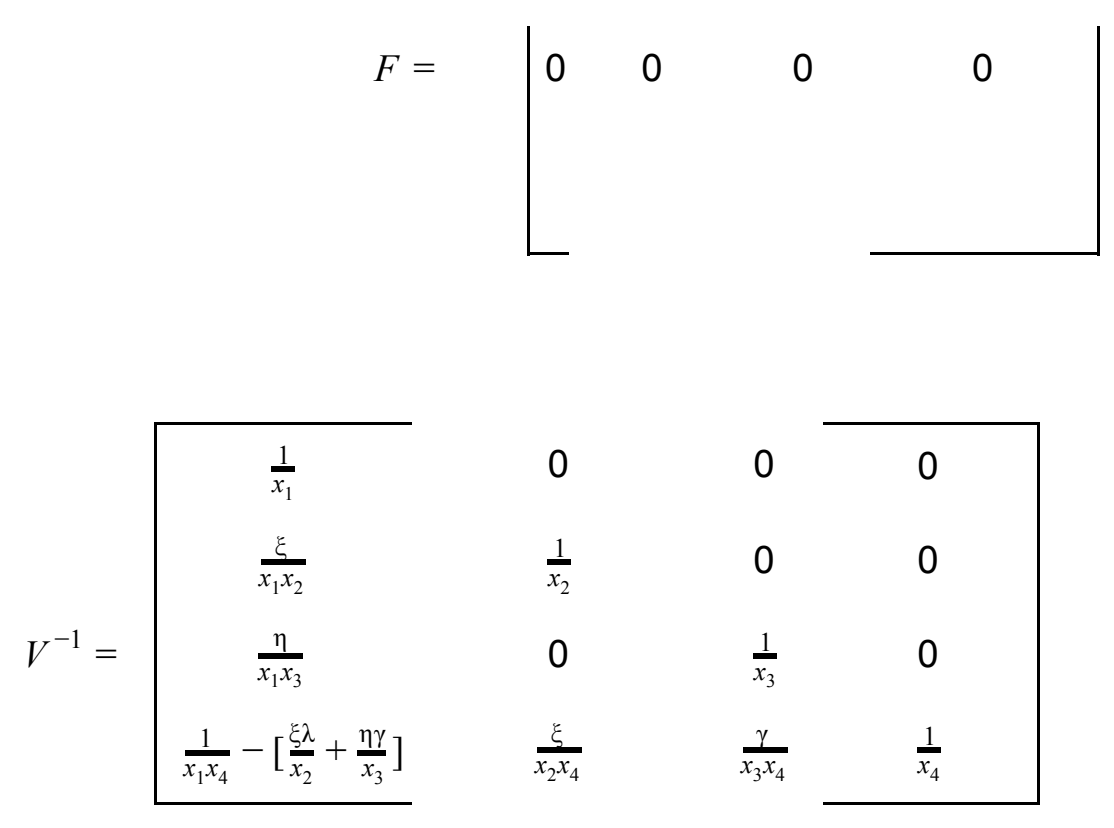

Let $x_{1}=(\mu+\eta+\xi+\gamma), x_{2}=(\lambda+\theta+\mu), x_{3}=(\mu+\gamma), x_{4}=(\mu+\delta+\alpha)$

$R_{0}=\operatorname{Trace}\left(F V^{-1}\right)$

$R_{0}=\frac{\beta_{A} \xi}{(\mu+\eta+\xi+\gamma)(\lambda+\theta+\mu)}+\frac{\beta_{I} \eta}{(\mu+\eta+\xi+\gamma)(\mu+\gamma)}+\frac{\beta_{Q}}{(\mu+\eta+\xi+\gamma)(\mu+\delta+\alpha)}\left[\frac{\xi \lambda}{(\lambda+\theta+\mu)}+\frac{\eta \gamma}{(\mu+\gamma)}\right]$

\section{Numerical Analysis}

\section{1: Parameter estimation}

To evaluate the reproduction number Ro of COVID-19 in the India population, we applied new infection observed in 2 days to 14 days incubation period interval of data obtained from [3,4,6] from Feb 11, 2020 to April 28, 2020. Then on average, 95\% Cl calculated of all Ro calculated, and it was found $\mathrm{RO}=6.27195 \% \mathrm{Cl}$ [4.26086, 8.281224] shown in figure (5). Figure (5) depicts the box plots of variation of reproduction number R0 from 2 days incubation to 14 days incubation period along with overall R0. We estimated that effective reproduction number $R(t)$ varied during Feb 11,2020 to April 28,2020 with median value ranging from $4.023595 \% \mathrm{Cl}[3.06453,4.9825]$. We estimated a decline in $\mathrm{R}(\mathrm{t})$ from late March, from $34.9295 \% \mathrm{CI}[3.8649,65.97227]$ on March 23, the week the lockdown started, to $1.5995 \% \mathrm{Cl}[1.28,1.60]$ on April 28,2020. The projected $\mathrm{R}(\mathrm{t})$ on May 14,2020 is $0.9795 \% \mathrm{Cl}[0.74,1.21]$.

To evaluate the reproduction number of COVID-19 in the world population, we applied new infection observed in 7 days to 14 days incubation period interval of data obtained 
from [3,4,9] from Feb 11, 2020 to April 25, 2020. Then on average, $95 \% \mathrm{Cl}$ calculated of all R0 calculated, and it was found R0 $=2.55679495 \% \mathrm{Cl} \quad[2.1189889,2.9945997]$ shown in figure (4). Figure (3) depicts the effective reproduction number $R(t)$ ranging from $[0.26,6.54]$. We found that the highest daily reproduction number $R(M a r .21,2020)$ is 6.54 and then declined in daily effective reproduction number $R(A p r 28,2020)$ is $\mathrm{R} 0=0.97 \leq 1$, shown in figure (3).

\section{Effective Reproduction Number of COVID-19 of India Population}

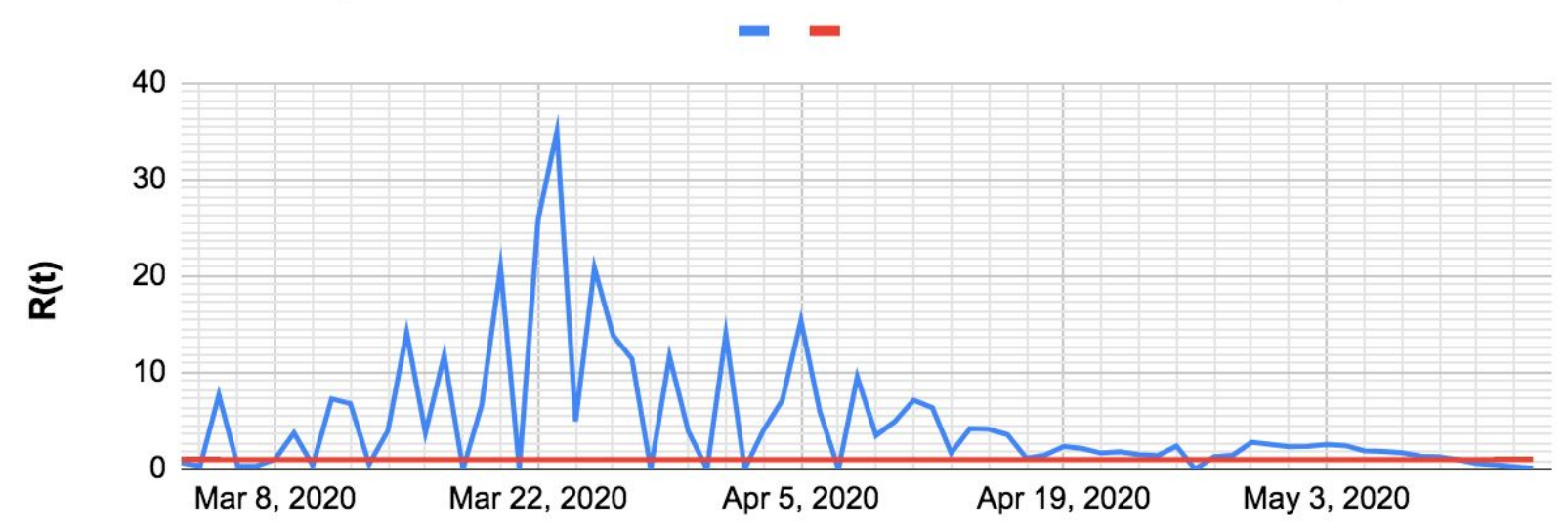

Figure (2)

\section{Global effective reproduction number $\mathrm{R}(\mathrm{t})$}

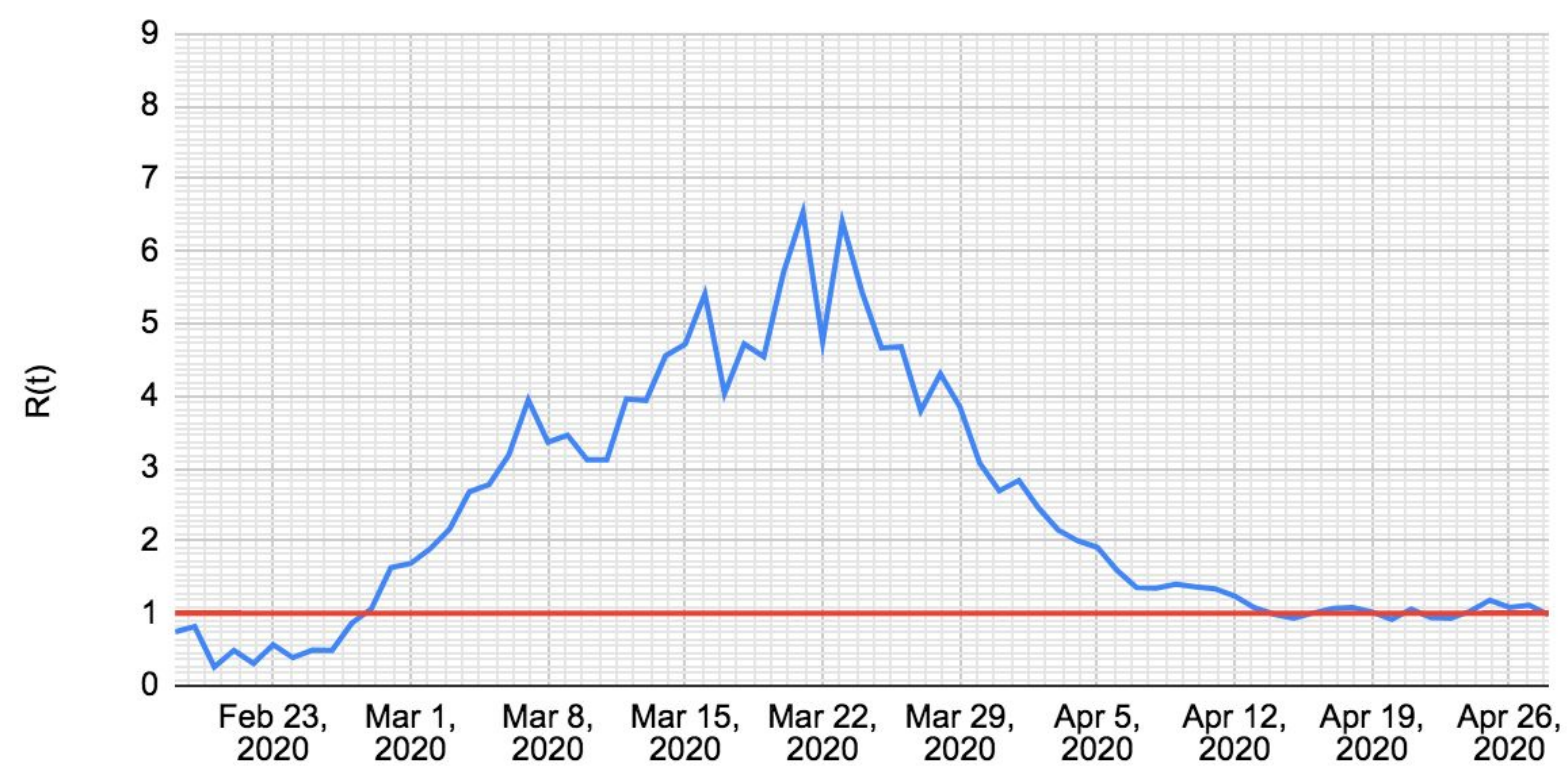

Figure (3) 


\section{Reproduction number of India Vs World}

40

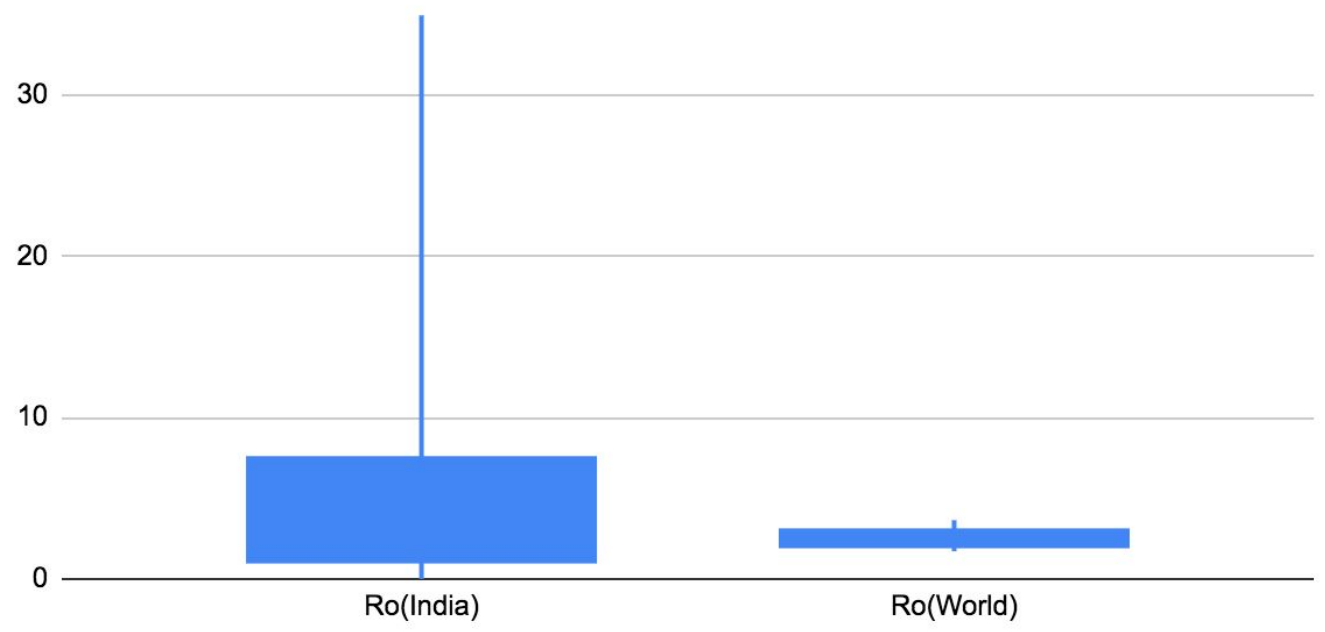

Figure (4): Reproduction number of India is R0 $=6.27195 \% \mathrm{Cl}$ [4.26086, 8.281224], and for World population is $\mathrm{R0}=2.55679495 \% \mathrm{Cl}[2.1189889,2.9945997]$.

\section{Box plot of Reproduction number based...}

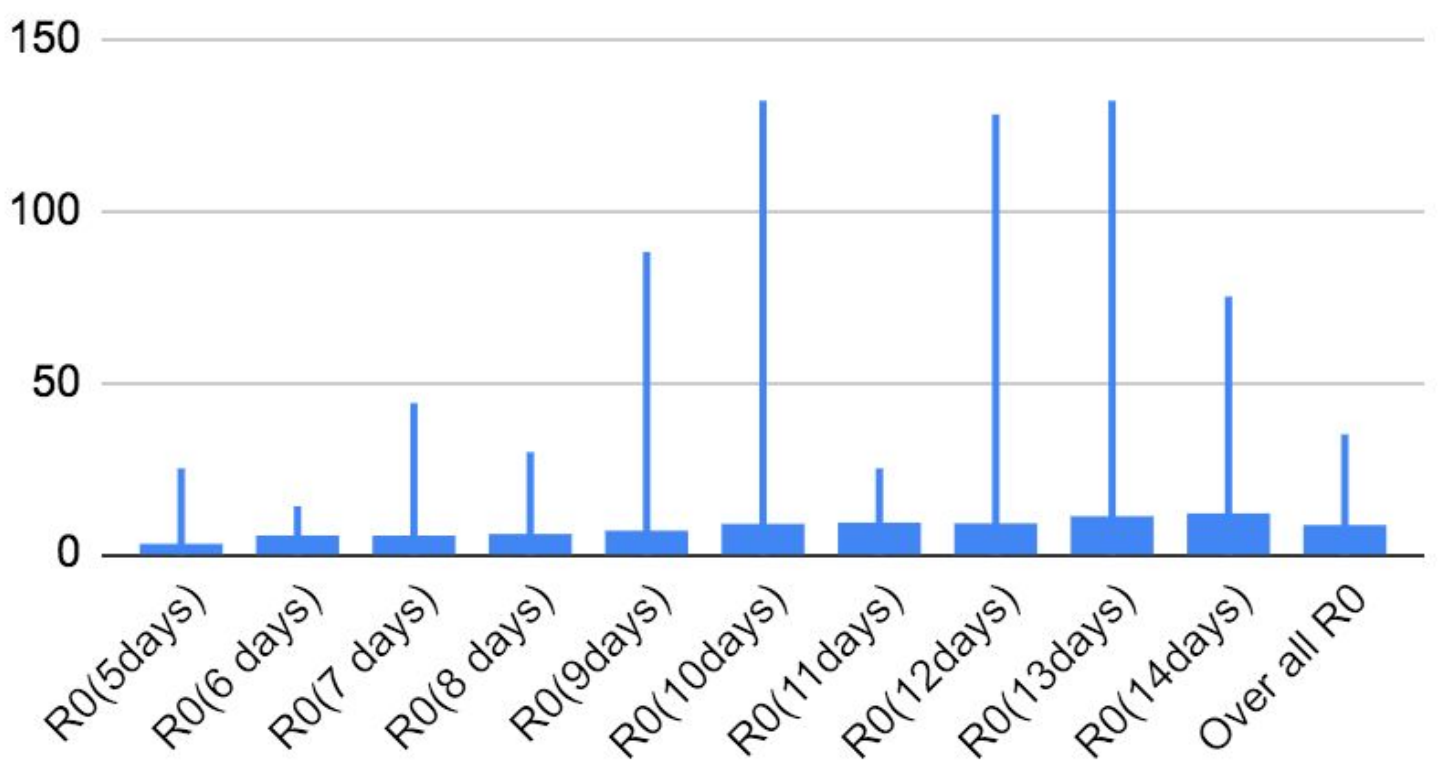

Figure (5): Reproduction number of India population is computed based on data observed from $\mathrm{WHO}$ situation report based on $95 \% \mathrm{Cl}$ for 5 to 14 days. 


\section{Box Plot of Infectivity and other parameters}

0.6

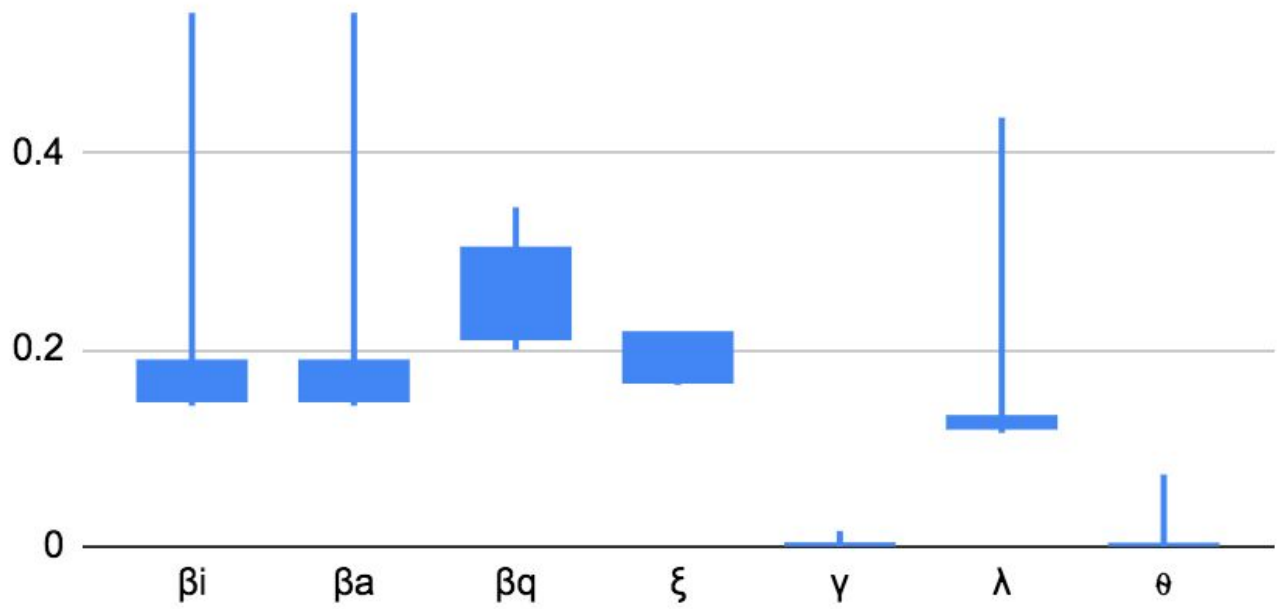

Figure (6): Infectivity parameters estimated by LHS PRCC methods on variation of range of reproduction number $\mathrm{RO}=6.27195 \% \mathrm{Cl}$ [4.26086, 8.281224]

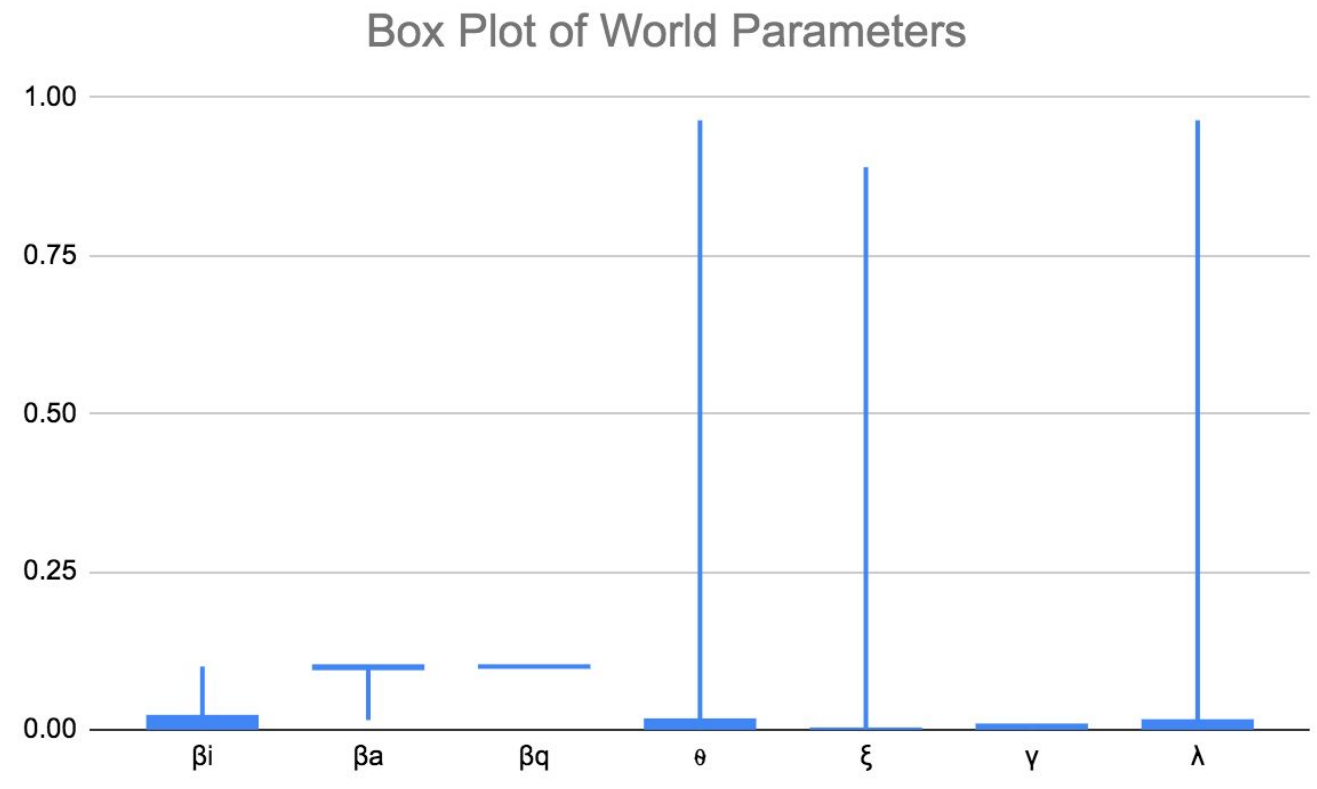

Figure (7): Infectivity parameter is estimated by LHS PRCC methods based on calculated World population reproduction number $\mathrm{R} 0=2.55679495 \% \mathrm{Cl}$ [2.1189889,2.9945997]

3.2. Infectivity Parameter estimation for India and World population 
We used Latin Hypercube Simulation Partial Rank Correlation coefficient (LHS PRCC) to estimate infectivity parameters from three route symptomatic Infectious, asymptomatic Infectious, and quarantine infectious for India and World populations. We estimated that infectivity rate from symptomatic Infectious for India population is $\beta \mathrm{i}$ $=0.201195 \% \mathrm{Cl}[0.12761,0.27467]$, while for world population is $\beta i=0.0137695 \% \mathrm{Cl}$ $[0.00175,0.02578]$, infectivity rate from Quarantine India population is $\beta \mathrm{q}$ is 0.2603 $95 \% \mathrm{Cl}[0.2265,0.29413]$, while for infectivity rate from world population is $\beta \mathrm{q}$ is 0.09974 $95 \% \mathrm{Cl}[0.0995,0.09998]$, and infectivity rate from asymptomatic infectious for India population is $0.201195 \% \mathrm{CI}[0.1276,0.27467]$, while asymptomatic infectious for world population is $\mathrm{Ba}$ is $0.0936195 \% \mathrm{Cl}[0.08368,0.10354]$ as well as death rate from Infectious class (symptomatic and asymptomatic - quarantine or not showing symptoms) for India population is $\delta=3.4 \%$, and corresponding rate from world population is $\delta=6.9 \%$. To best fit the model with data from We found the $4.2 \%$ confirmed infected with incubation period to fit the model is 12 days for the India population and $10.67 \%$ confirmed infected with incubation period to fit the model is 7 days. The recovery parameter $\alpha$ at hospitalization treatment was observed at $12.5 \%$ with 14 days recovery time, and $29.31 \%$ with 32 days recovery time for India and World population respectively, and recovery parameter at home treatment was $99.74 \%$ with 14 days recovery time, and $99.77 \%$ with 14 days recovery time for India and World population respectively.. Onset of symptoms to death from hospitalization is $3.4 \%$ and $6.9 \%$ for India, and the world population respectively. We found $15.32 \%$, and $14.39 \%$ of the asymptomatic infectious population in India and World population developed the symptoms respectively, and $0.74 \%$, and $0.14 \%$ developed Immunity for India and the World population respectively. We found more contribution in reproduction numbers are $1.279895 \% \mathrm{Cl}[1.13929,1.40667$ ]from asymptomatic infectious , $5.3866195 \% \mathrm{Cl}$ [4.57022, 6.20299] from quarantined population, and least contribution is $0.0035495 \%$ $\mathrm{Cl}[0.00221,0.00487]$ from infectious populations for India populations. We found more contribution in reproduction number are $1.090495 \% \mathrm{Cl}[0.438,1.743]$ from asymptomatic infectious, $0.004695 \% \mathrm{Cl}[0.00172,0.0075]$ from infectious population and least $0.002695 \% \mathrm{CI}-0.0006,0.0059]$ from quarantine populations for the World populations. All parameters values are mentioned in Table 1.

\begin{tabular}{|c|c|c|c|c|c|}
\hline $\begin{array}{l}\text { Parame } \\
\text { ter }\end{array}$ & India Population & Source & $\begin{array}{l}\text { Parame } \\
\text { ter }\end{array}$ & World Population & Source \\
\hline$\beta i$ & $\begin{array}{l}0.201195 \% \mathrm{Cl} \text { [0.12761, } \\
0.27467]\end{array}$ & fitted & $\beta \mathrm{i}$ & $\begin{array}{l}0.0137695 \% \mathrm{Cl} \\
{[0.00175,0.02578]}\end{array}$ & fitted \\
\hline$\beta a$ & $\begin{array}{l}0.201195 \% \text { CI[0.1276, } \\
0.27467]\end{array}$ & fitted & $\beta a$ & $\begin{array}{l}0.0936195 \% \mathrm{CI}[0.08368, \\
0.10354]\end{array}$ & fitted \\
\hline$\beta q$ & 0.2603 95\% Cl [0.2265, & fitted & $\beta q$ & $0.0997495 \% \mathrm{Cl}$ & fitted \\
\hline
\end{tabular}




\begin{tabular}{|c|c|c|c|c|c|}
\hline & 0.29413 & & & {$[0.0995,0.09998]$} & \\
\hline$\theta$ & $\begin{array}{l}0.007495 \% \text { Cl [-0.0067, } \\
0.0214]\end{array}$ & fitted & $\theta$ & $\begin{array}{l}0.144295 \% \mathrm{Cl}[-0.021, \\
0.30889]\end{array}$ & fitted \\
\hline$\xi$ & $\begin{array}{l}0.1923 \text { 95\% Cl [0.1772, } \\
0.2074]\end{array}$ & fitted & $\xi$ & $\begin{array}{l}0.04957495 \% \mathrm{Cl} \\
{[-0.055,0.1539]}\end{array}$ & fitted \\
\hline Y & $\begin{array}{l}0.002695 \% \text { Cl [-0.0009, } \\
0.006]\end{array}$ & fitted & $\mathrm{Y}$ & $\begin{array}{l}0.002395 \% \mathrm{Cl}[0.0009, \\
0.0037]\end{array}$ & fitted \\
\hline$\lambda$ & $\begin{array}{l}0.1531595 \% 0.0929, \\
0.21344]\end{array}$ & fitted & $\lambda$ & $\begin{array}{l}0.143995 \% \mathrm{Cl}[-.021, \\
0.3087]\end{array}$ & fitted \\
\hline ym & $\begin{array}{l}0.9974 \text { 95\% Cl [ 0.99398, } \\
1.00088]\end{array}$ & $\begin{array}{l}\text { calculate } \\
\text { d }\end{array}$ & ym & $\begin{array}{l}0.9977 \text { 95\% Cl [0.9962, } \\
0.9991]\end{array}$ & $\begin{array}{l}\text { calcula } \\
\text { ted }\end{array}$ \\
\hline$R \theta$ & $\begin{array}{l}5.3866195 \% \text { Cl [4.57022, } \\
6.20299]\end{array}$ & Fitted & $\mathrm{R} \theta$ & $\begin{array}{l}0.002695 \% \mathrm{Cl}[-0.0006 \\
0.0059]\end{array}$ & fitted \\
\hline$\eta$ & 0.003471122 & 5,7 & $n$ & 0.01523618429 & 7 \\
\hline$a$ & 0.008942622336 & 11 & $a$ & 0.009160730313 & 11 \\
\hline$\delta$ & 0.0343591537 & 5,11 & $\delta$ & 0.06914 & 11 \\
\hline$\mu$ & $7.3 / 1000$ & $3,4,10$ & $\mu$ & $4 / 1000$ & $3,4,10$ \\
\hline$B$ & $18.7 / 1000$ & 10 & $B$ & $11.9 / 1000$ & 10 \\
\hline$N$ & $1,380,004,385$ & 10 & $N$ & 7774218060 & 10 \\
\hline Ro & $\begin{array}{l}\text { 6.271 95\% Cl [4.26086, } \\
8.281224]\end{array}$ & \begin{tabular}{|l|} 
calculate \\
d
\end{tabular} & RO & $\begin{array}{l}2.556794 \\
{[2.1189889,2.9945997]}\end{array}$ & $\begin{array}{l}\text { calcula } \\
\text { ted }\end{array}$ \\
\hline $\mathrm{Ri}$ & $\begin{array}{l}0.0035495 \% \mathrm{Cl}[0.00221, \\
0.00487]\end{array}$ & fitted & $\mathrm{Ri}$ & $\begin{array}{l}0.004695 \% \mathrm{Cl}[0.00172, \\
0.0075]\end{array}$ & fitted \\
\hline $\mathrm{Ra}$ & $\begin{array}{l}1.279895 \% \mathrm{Cl} \text { [1.13929, } \\
1.40667]\end{array}$ & fitted & $\mathrm{Ra}$ & $\begin{array}{l}1.090495 \% \mathrm{Cl}[0.438, \\
1.743]\end{array}$ & fitted \\
\hline
\end{tabular}

Table 1: Parameters, their values and reproduction numbers for India and World Populations.

\section{Numerical Analysis:}

In this section, using Runge-Kutta-Fehlberg method of order 4 and 5, we numerically simulate our system (1) and (2) with real parametric values as given in Table 1 and MATLAB is used to simulate the systems. We run the simulation for previous 78 days in consideration to fit the model for India populations, and it clearly indicates that major exposure occurs from the end of November 24 as we have data from Feb 11, 2020. 
We found the peak occurred on May 4, with 53,100 total confirmed cases shown in figure (8). The trajectory of the graph in figure (8) predicted May 14, with a total 73,800 cumulative number of infectious population in India populations, will be a crucial time when the graph has a sudden fall that indicates either faster recovery or death or both. The cumulative of asymptomatic infectious population by May 18, 2020 will be 23.22 millions, and total quarantine populations by June 1, 2020 will be 52.8 millions shown in figure (10).

We ran the simulation for the previous 83 days to fit the model for World populations, and clearly indicate that major exposure occurs from the end of November 19, 2019 as I used data from Feb. 11, 2020. We found the peak has occured on April 25, 2020 with 2,719,897 confirmed positive number of cases based on preventive measure of World populations shown in figure (9), and trajectory of the graph in figure (9) predicted May $7,2020,3.772$ million cumulative number of infectious population in world populations, will be a crucial time when the graph has fall that indicates either faster recovery or death or both, even cases will still increase but at gradual decrease rate. The cumulative of asymptomatic infectious populations by May 9, 2020 will be 818.3 millions, and cumulative number of quarantined populations by May 18, 2020 will be 1.111 billions.

The total dynamical systems of each class on both India populations, and the World populations are shown in figure (12), and figure (13). These calculations are based on preventive measures (social lockdown), the situation would be worse if preventive measures are lifted. 


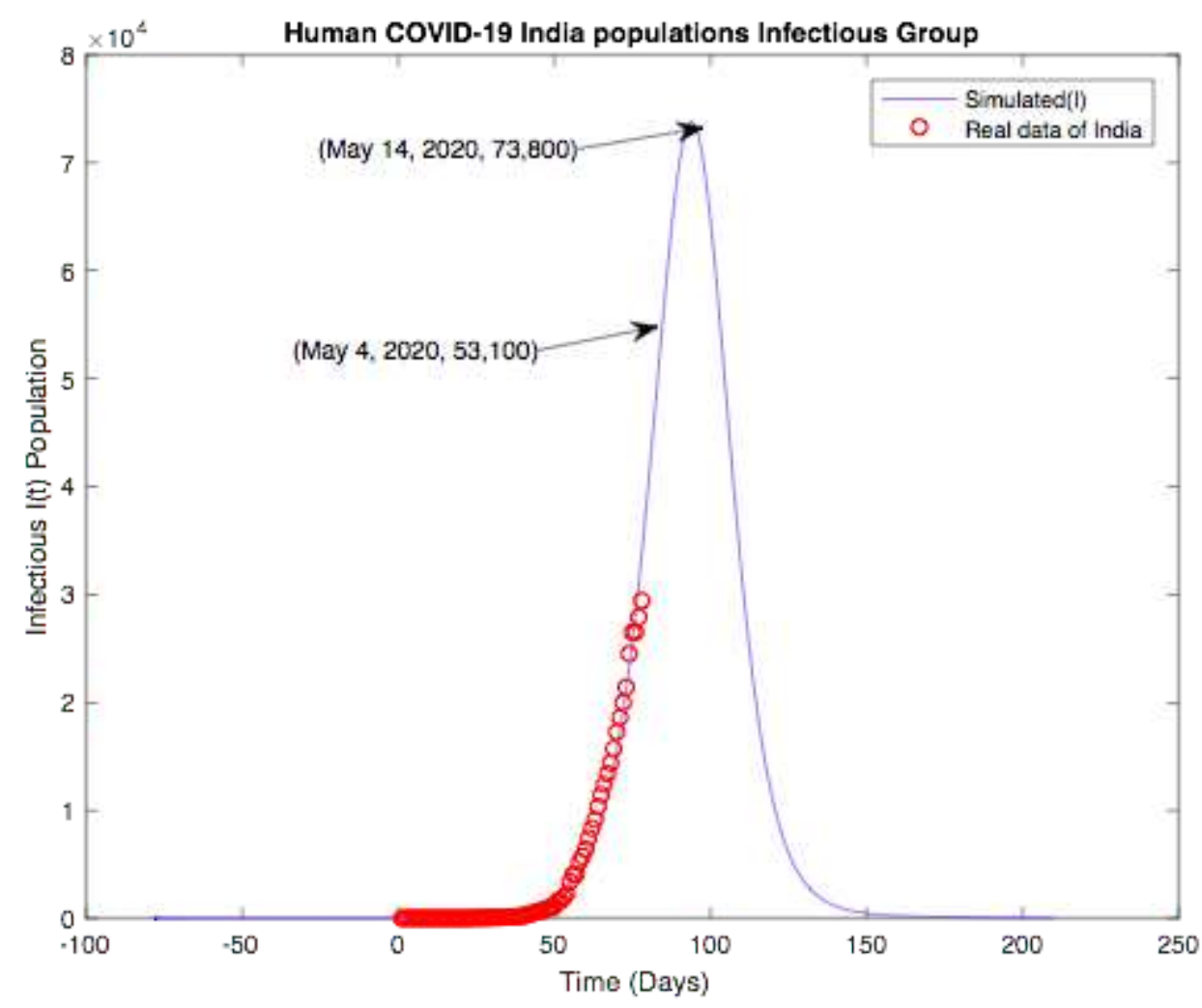

Figure (8) 


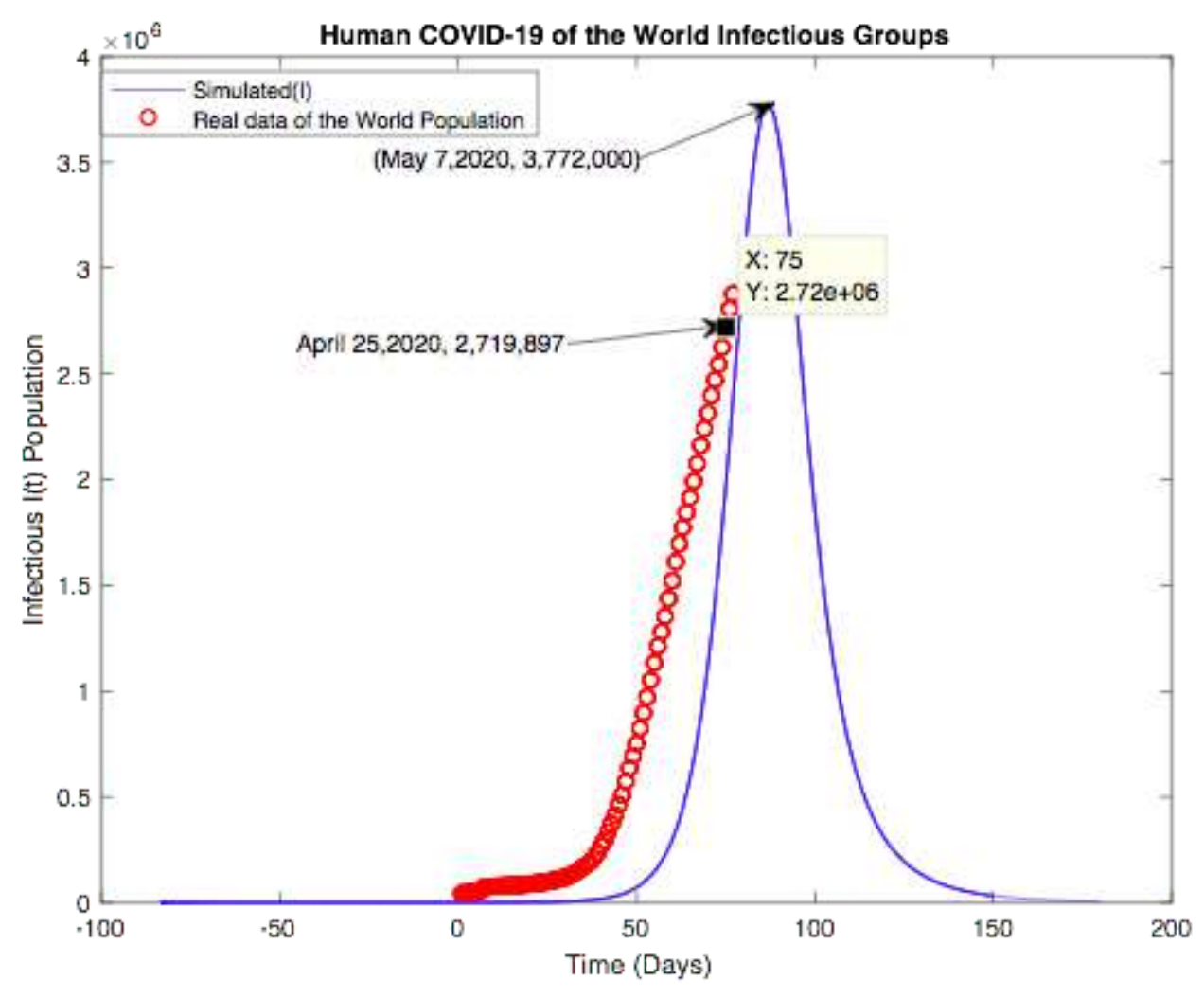

Figure (9) 


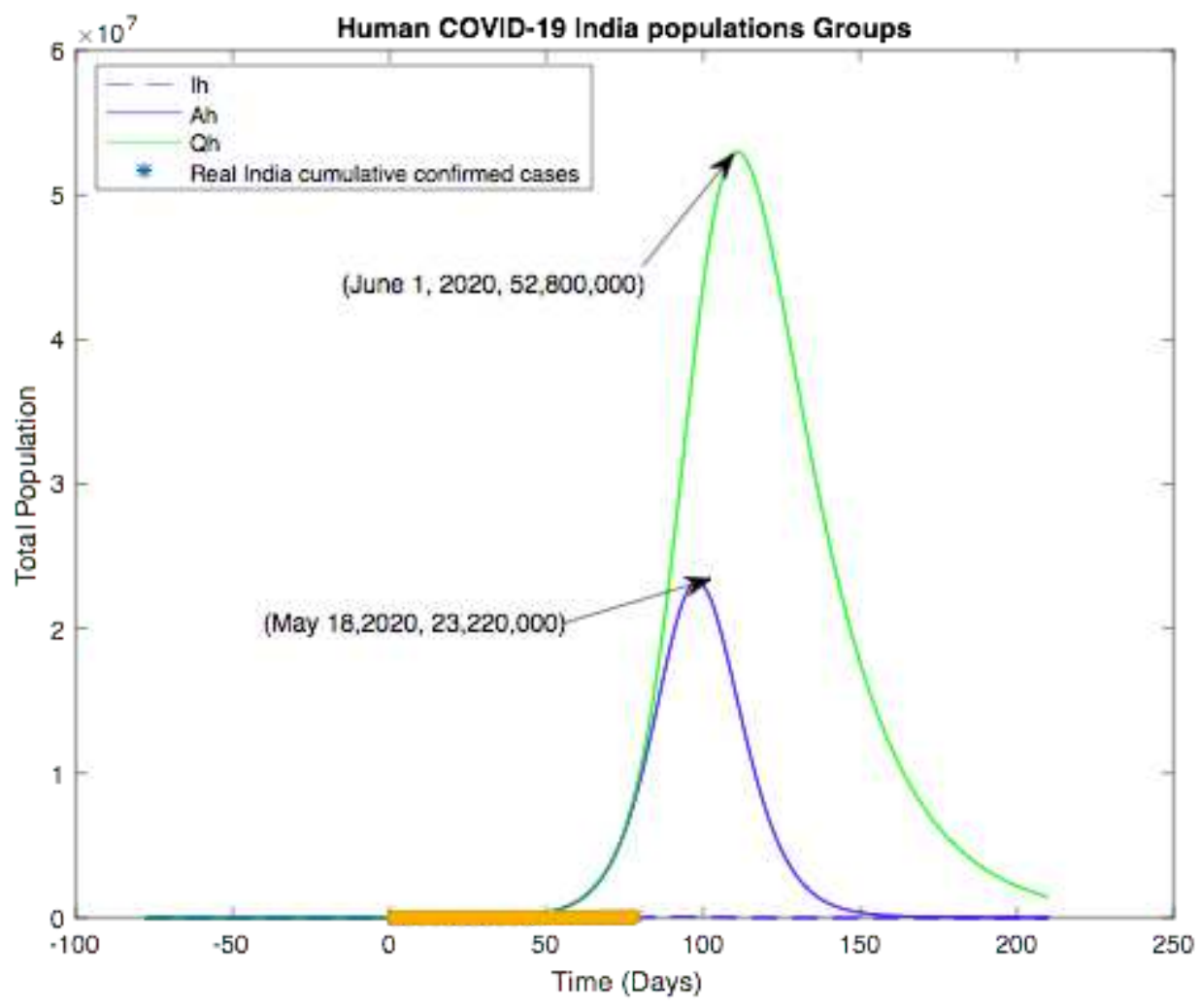

Figure (10) 


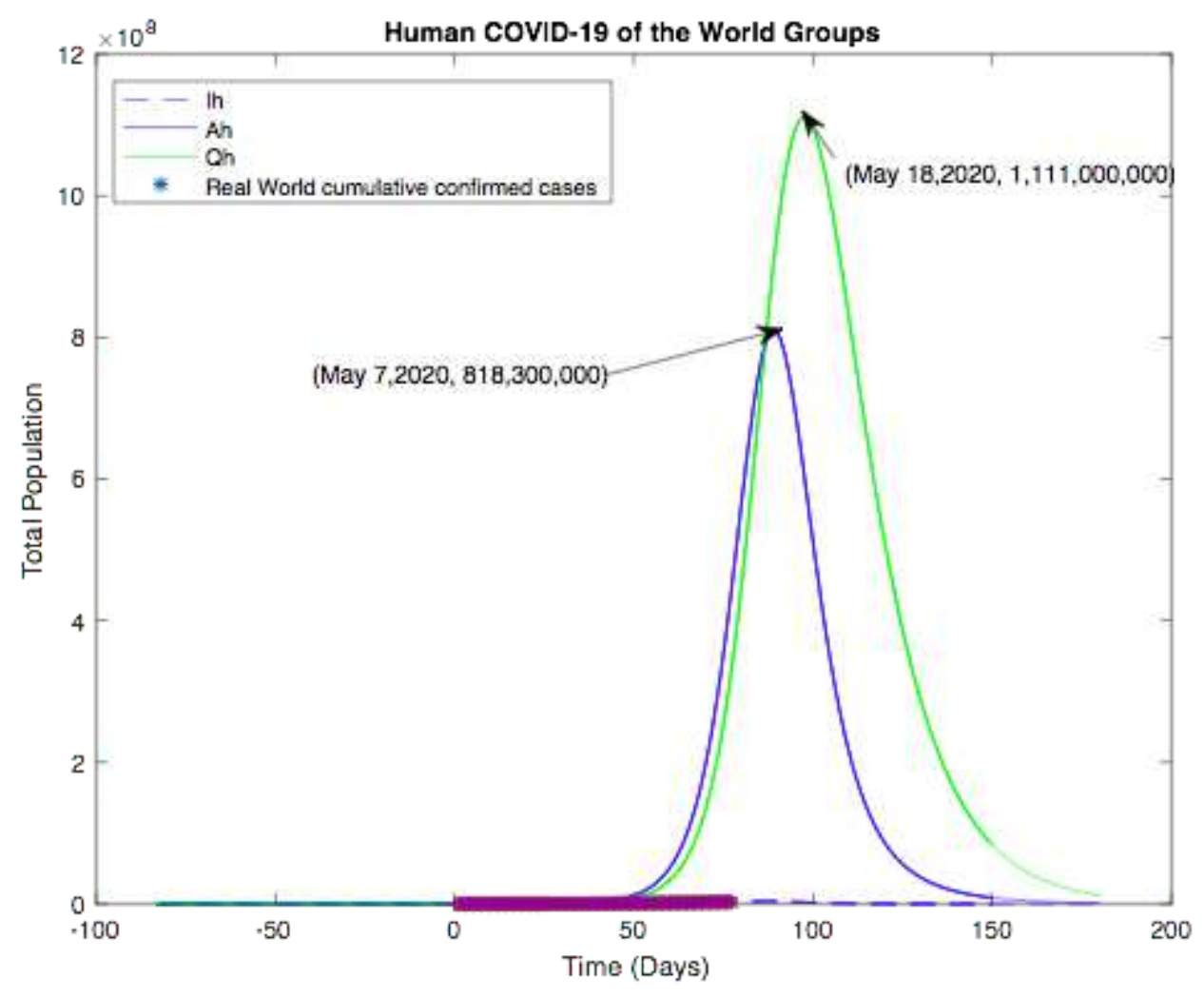

Figure (11) 


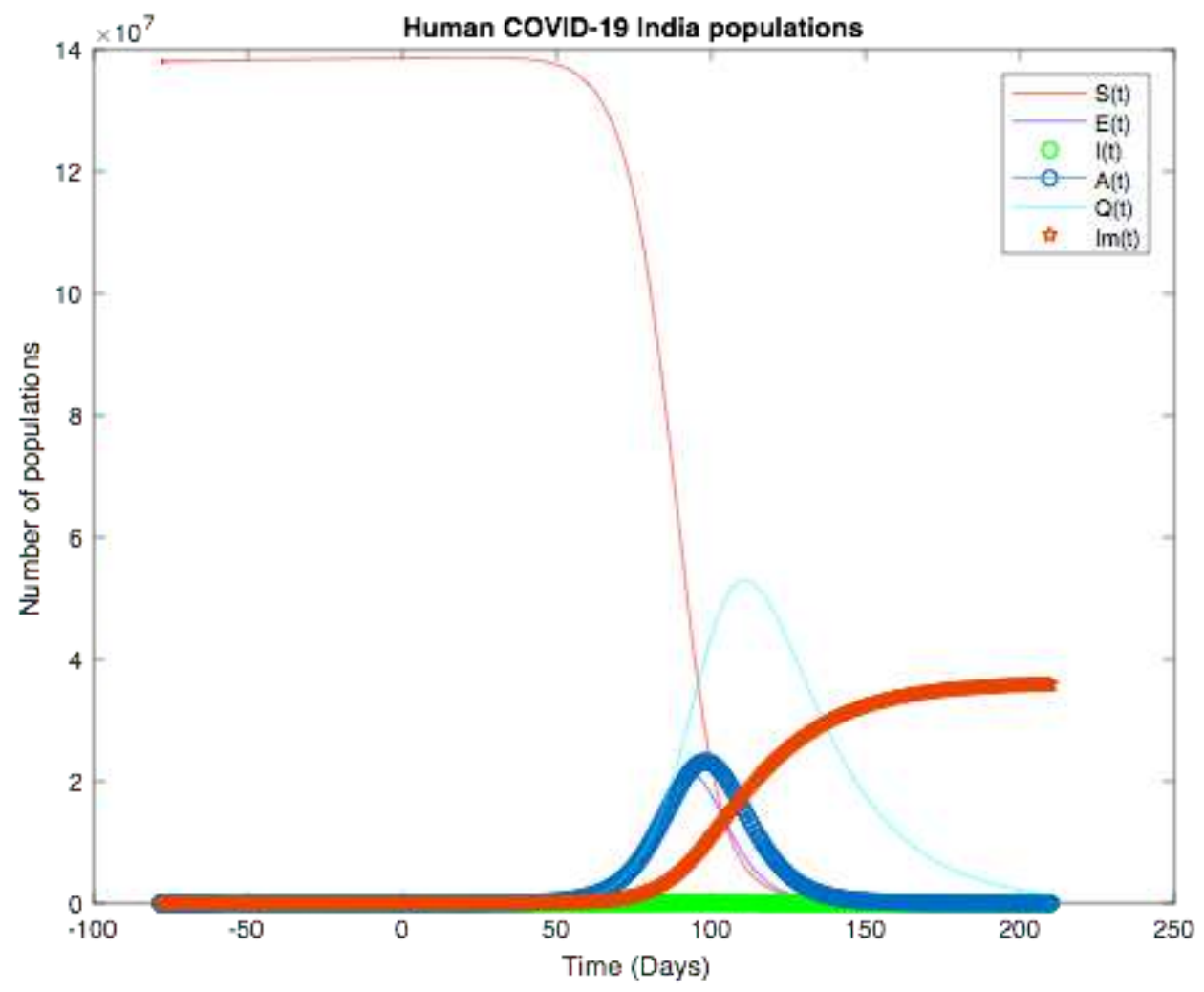

Figure (12) 




Figure (13)

\section{Conclusion:}

$S E I A Q I_{M}$ (susceptible-exposed-infectious-asymptomatic-quarantine-recovered) model is what we use to analyze COVID-19's transmission dynamics in the India and World populations. We found that India reached its peak reproduction number on March 23 $(\mathrm{R} 0=34.9)$, but since then, the basic reproduction number has lowered to 1.59 (April 28th). However, that is still above the control line which sits at 1 , so the outbreak will continue until $R 0 \leq 1$ that will reach on May 14 th $\mathrm{R} 0=0.97$. We found that World reached its peak reproduction number on March $21(\mathrm{R} 0=6.48)$, but since then the basic reproduction number has lowered to $\mathrm{R} 0=0.97 \leq 1$ (April 28), and it will reach maximum on May 7, 2020, 3.772 million cumulative number of infectious population in world populations.

We found the peak of COVID-19 for India's population will be occured on May 4, 2020 with a cumulative number of cases 53,100. We calculated the average basic reproduction numbers for the India and Global outbreaks. These numbers were R0 = $6.27195 \% \mathrm{Cl}[4.26086,8.281224]$ and $\mathrm{RO}=\mathbf{2 . 5 5 6 7 9 4}$ 95\% Cl [2.1189889,2.9945997] respectively, with the India being the highest in the reproduction number on March 23 $(\mathrm{R} 0=34.9)$, and after strict lockdown it could lowered till 1.59 on April 28th, it clearly 
indicates the extension of phase 3 lockdown must continue in India. We estimated the reproduction number will reach $0.0995 \% \mathrm{CI}[0.089,0.14]$ on May 14, 2020 if the follow the same prevention measure.

We fit our simulation to the actual cumulative cases and ran the simulation for an extended amount of time (150 days) to predict the life of the outbreak. We found that by July 9, 2020 the situation will be under control in both India and world populations. So, despite the basic reproduction number dropping significantly since March $23(R(t)=$ $34.9,6.58$ to April 28th where $R(t)=1.59$, and 0.97$)$, due to it being above the control line, our simulations show that COVID-19 will continue to spread easily through the India and World population well into July of 2020.

\section{Competing Interest: The authors declare no competing interest. Funding: The authors received no external funding for this research.}

\section{Designed the project (D. S.); performed simulations (D. S.), performed analysis of the data (D. S.), wrote the paper (D. S.)}

Acknowledgements

Thanks to Dr Prem Kumar Sinha, Senior Scientist of Roswell Biotechnologies, whose contribution in Language correction and some modifications is duly acknowledged.

\section{6: References:}

1) COVID-19 CORONAVIRUS PANDEMIC. (2020). Worldometer.

2) Coronavirus disease 2019 (COVID-19) Situation Report (2020). World Health Organization.

3) Central Intelligence Agency. (2020, March 31). The World Factbook.

4) Countries in the world by population. (2020). Worldometer.

5) https://www.covid19india.org/

6) B. Paital et al. / Science of the Total Environment 728 (2020) 138914

7) https://informationisbeautiful.net/visualizations/covid-19-coronavirus-infographic-datapack/

8) Sinha, Durgesh and Klahn, Nicholas, Mathematical Modeling Study of the 2020 CoVID-19 Outbreak in the United States (April 12, 2020). Available at SSRN: https://ssrn.com/abstract=3573877 or http://dx.doi.org/10.2139/ssrn.3573877

9) Chatterjee $\mathrm{K}$ et al., Healthcare impact of COVID-19 epidemic in India: A stochastic mathematical model, Medical Journal Armed Forces India, https://doi.org/10.1016/j.mjafi.2020.03.022

10) https://www.worldometers.info/world-population/

11) https://www.worldometers.info/coronavirus/

12) https://ourworldindata.org/what-can-data-on-testing-tell-us-about-the-pandemic 


\section{Figures}

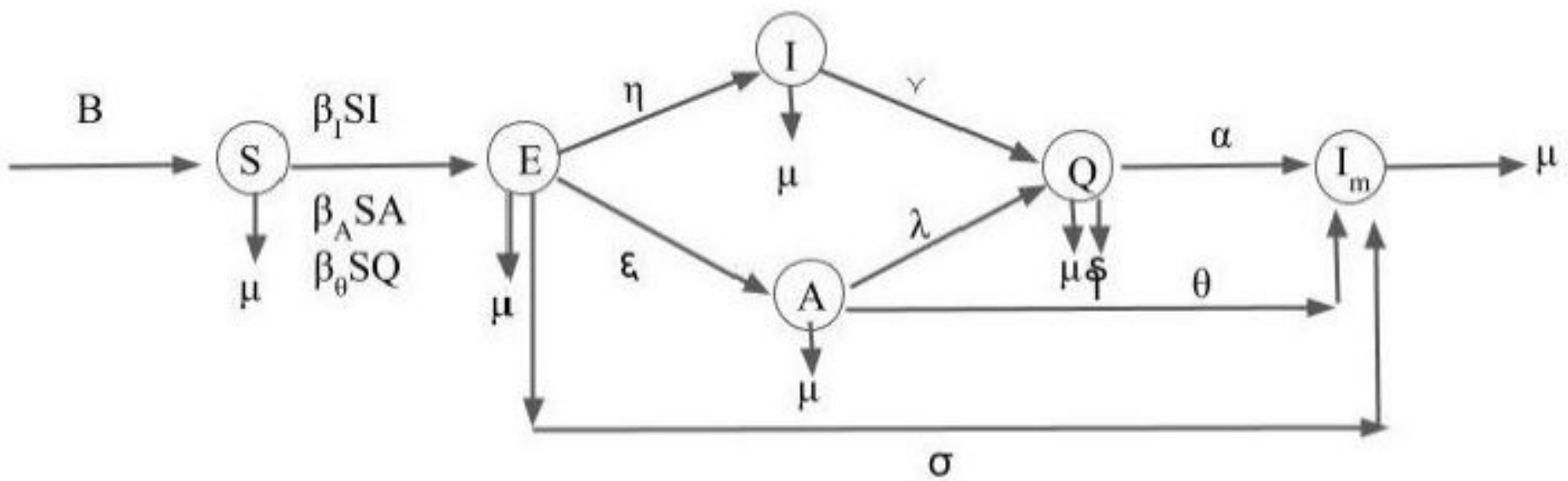

Figure 1

$S(t)$ : Susceptible humans in time $t E(t)$ : Exposed humans in time $t I(t)$ : Infectious humans in time $t$ $\operatorname{Im}(\mathrm{t})$ : Recovered humans with Immunity in time $\mathrm{A}(\mathrm{t})$ : Asymptomatic infectious human in time $\mathrm{Q}(\mathrm{t})$ : Quarantine human in time $N(t)$ : Total human population in time $t B$ : Birth rate of humans $\beta i$ : Infectivity rate of COVID-19 from Symptomatic infectious class $\beta A$ : Infectivity rate of COVID-19 from Asymptomatic population class $\beta \Theta$ : Infectivity rate of COVID-19 from Quarantine population class $\eta$ : Rate of transition from exposed to infected humans $a$ : Rate of transition from Quarantine to recovered humans $\sigma$ : Rate of Immune humans from COVID-19 $\mathrm{y}$ : Rate of transition from Infected class to Quarantine class $\xi$ : Rate of transition from exposed to Asymptomatic infected class $\lambda$ : Rate of transition from Asymptomatic class to Quarantine class $\Theta$ : Rate of transition from Asymptomatic class to Recovered class with Immunity $\mu$ : Natural death rate of humans $\delta$ : Death rate of humans due to COVID-19

\section{Effective Reproduction Number of COVID-19 of India Population}

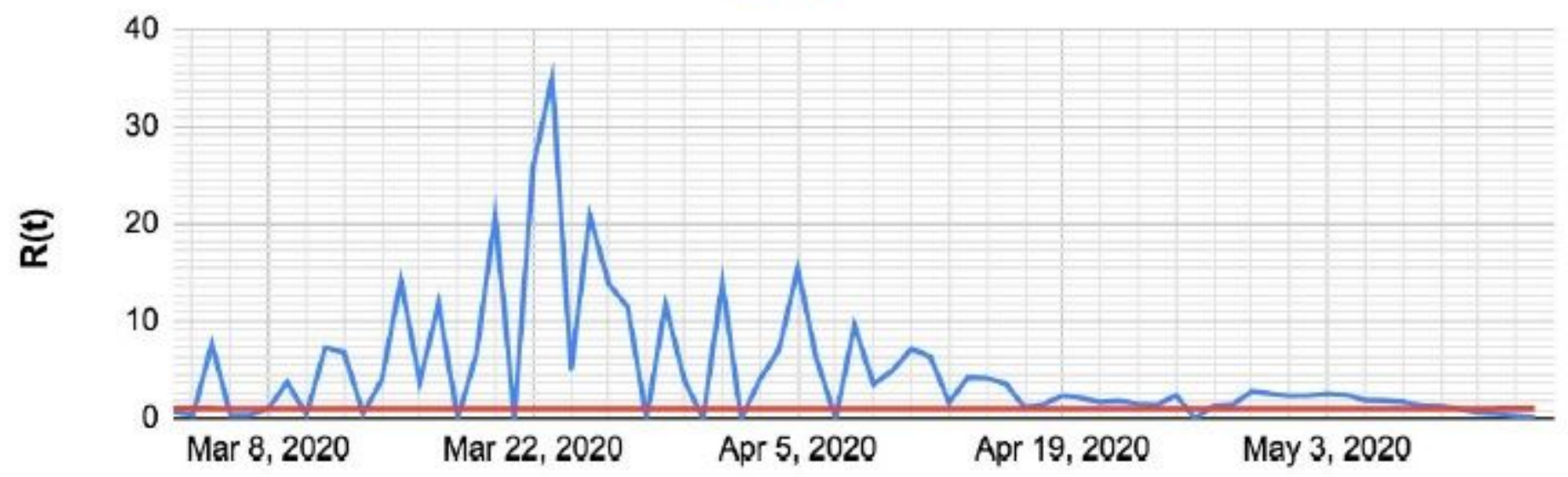

Figure 2 


\section{Global effective reproduction number $\mathrm{R}(\mathrm{t})$}

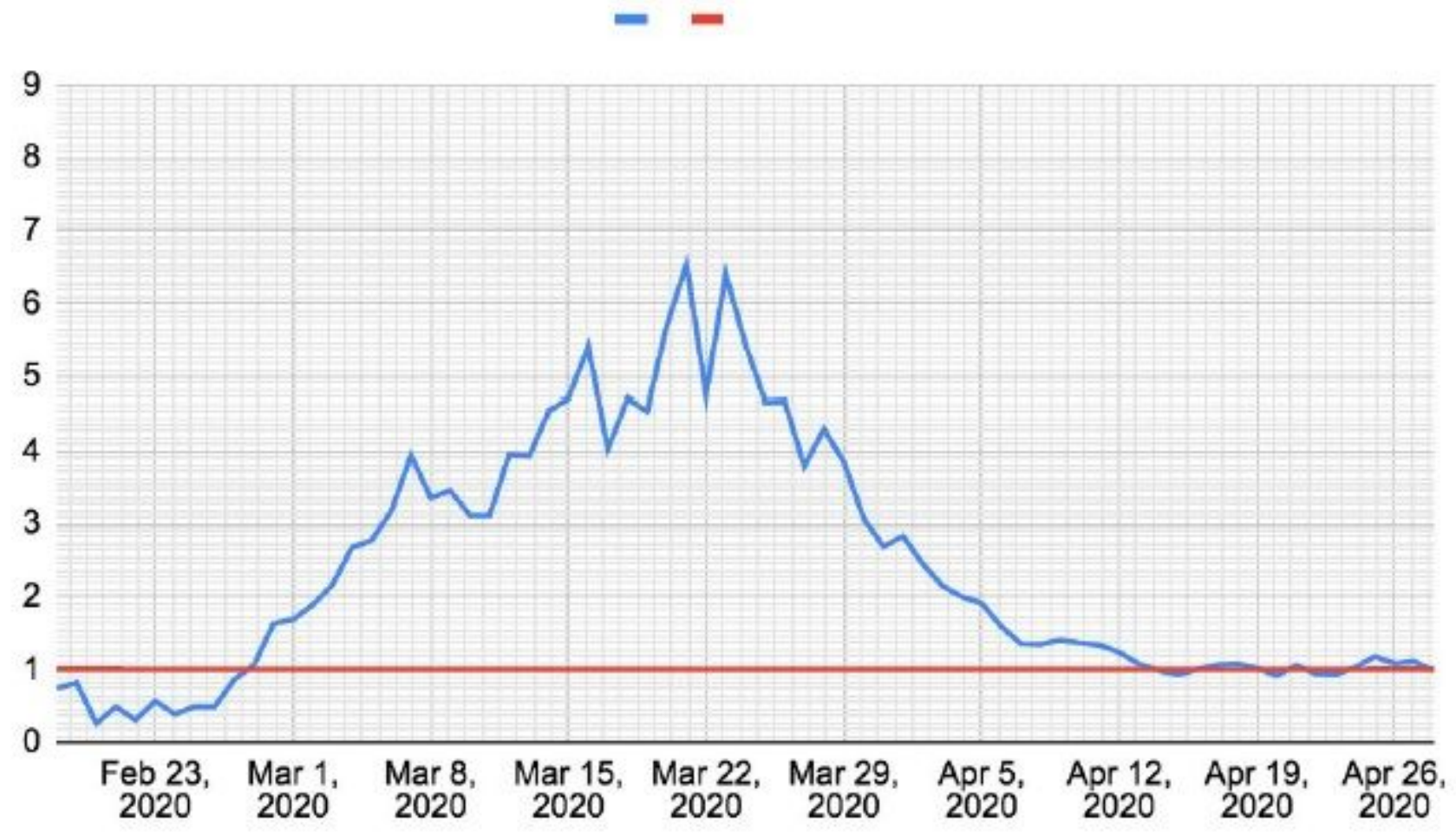

Figure 3

Global effective reproduction number $\mathrm{R}(\mathrm{t})$

Reproduction number of India Vs World

40

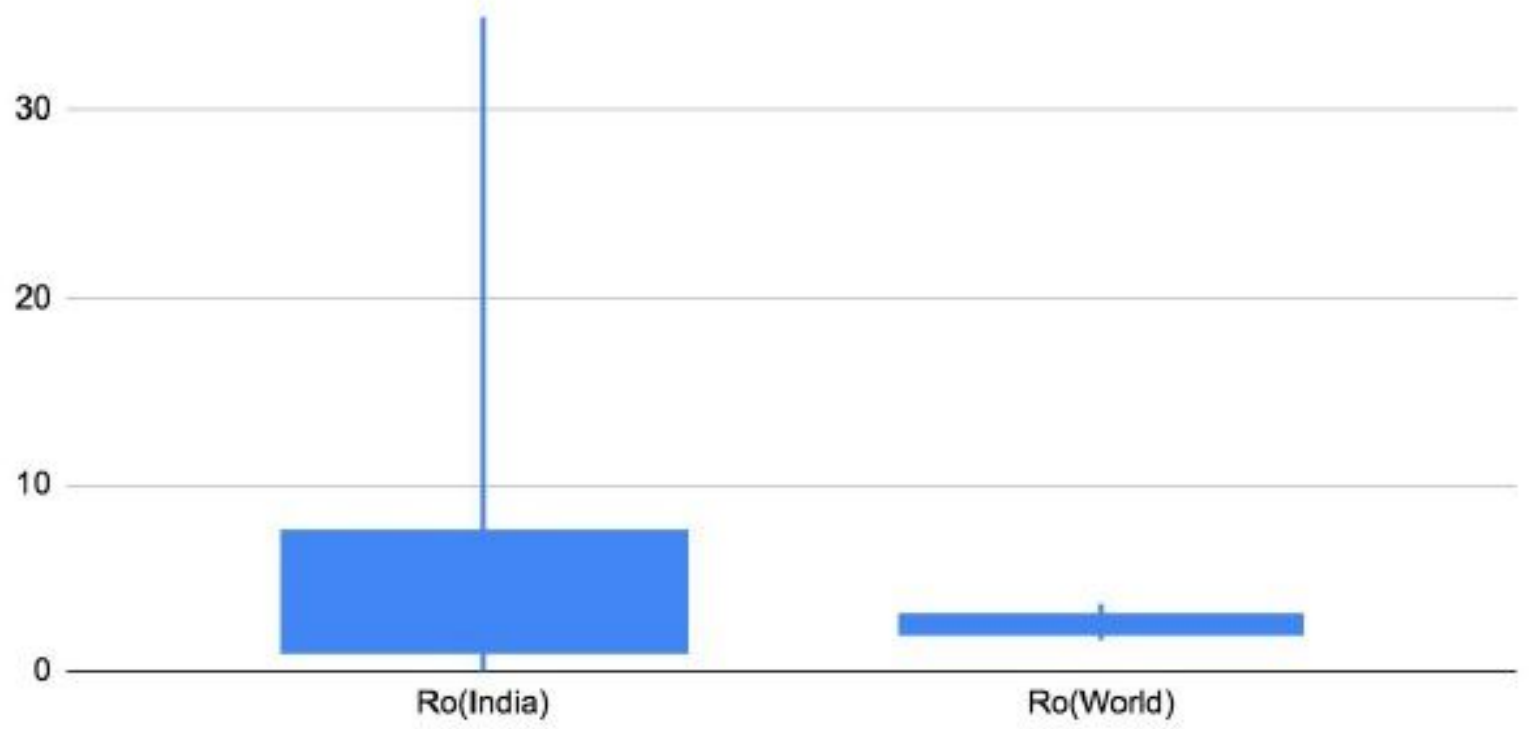

Figure 4 
Reproduction number of India is R0 $=6.27195 \% \mathrm{Cl}[4.26086,8.281224]$, and for World population is R0 $=2.55679495 \% \mathrm{Cl}[2.1189889,2.9945997]$.

\section{Box plot of Reproduction number based...}

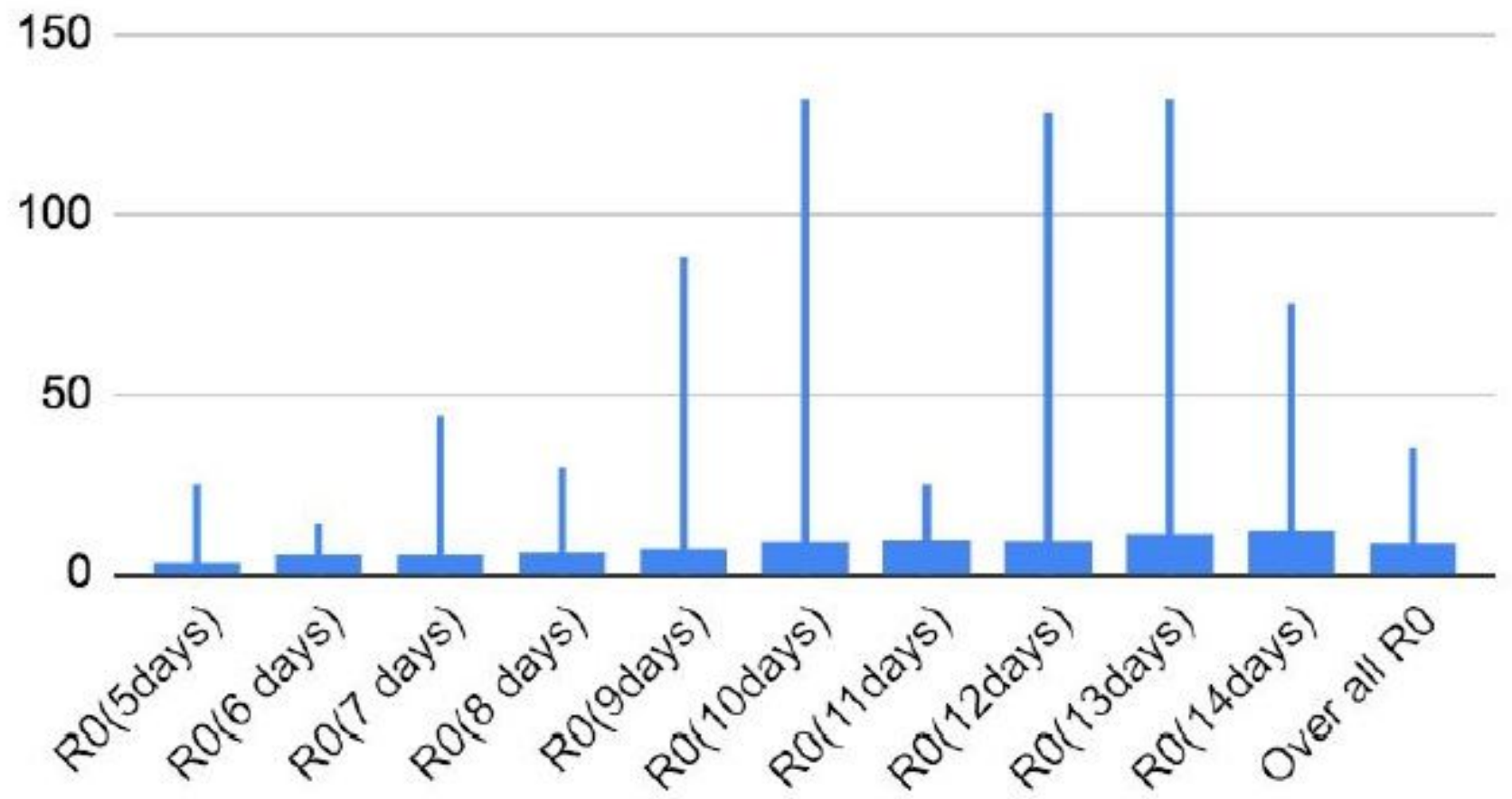

Figure 5

Reproduction number of India population is computed based on data observed from WHO situation report based on $95 \% \mathrm{Cl}$ for 5 to 14 days.

\section{Box Plot of Infectivity and other parameters}

0.6

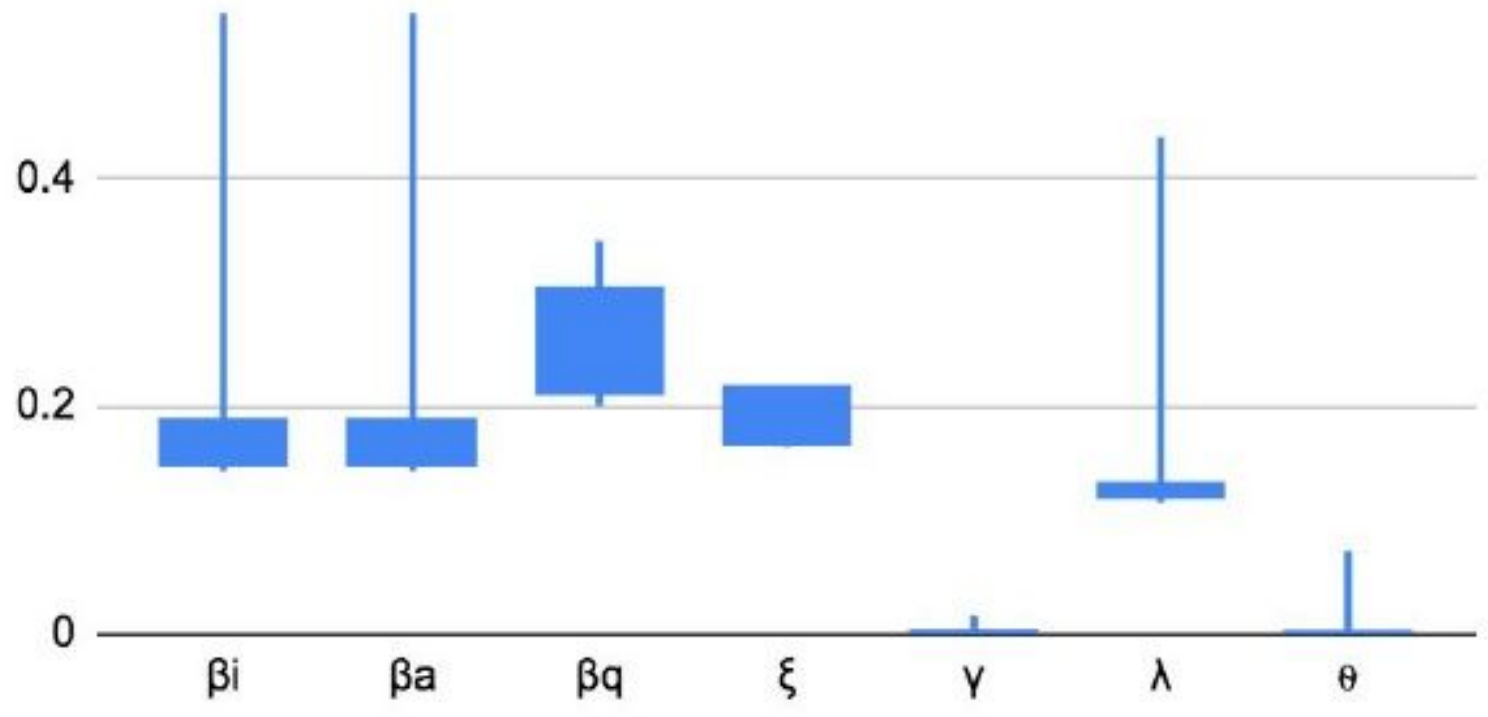


Figure 6

Infectivity parameters estimated by LHS PRCC methods on variation of range of reproduction number R0 $=6.27195 \% \mathrm{Cl}[4.26086,8.281224]$

\section{Box Plot of World Parameters}

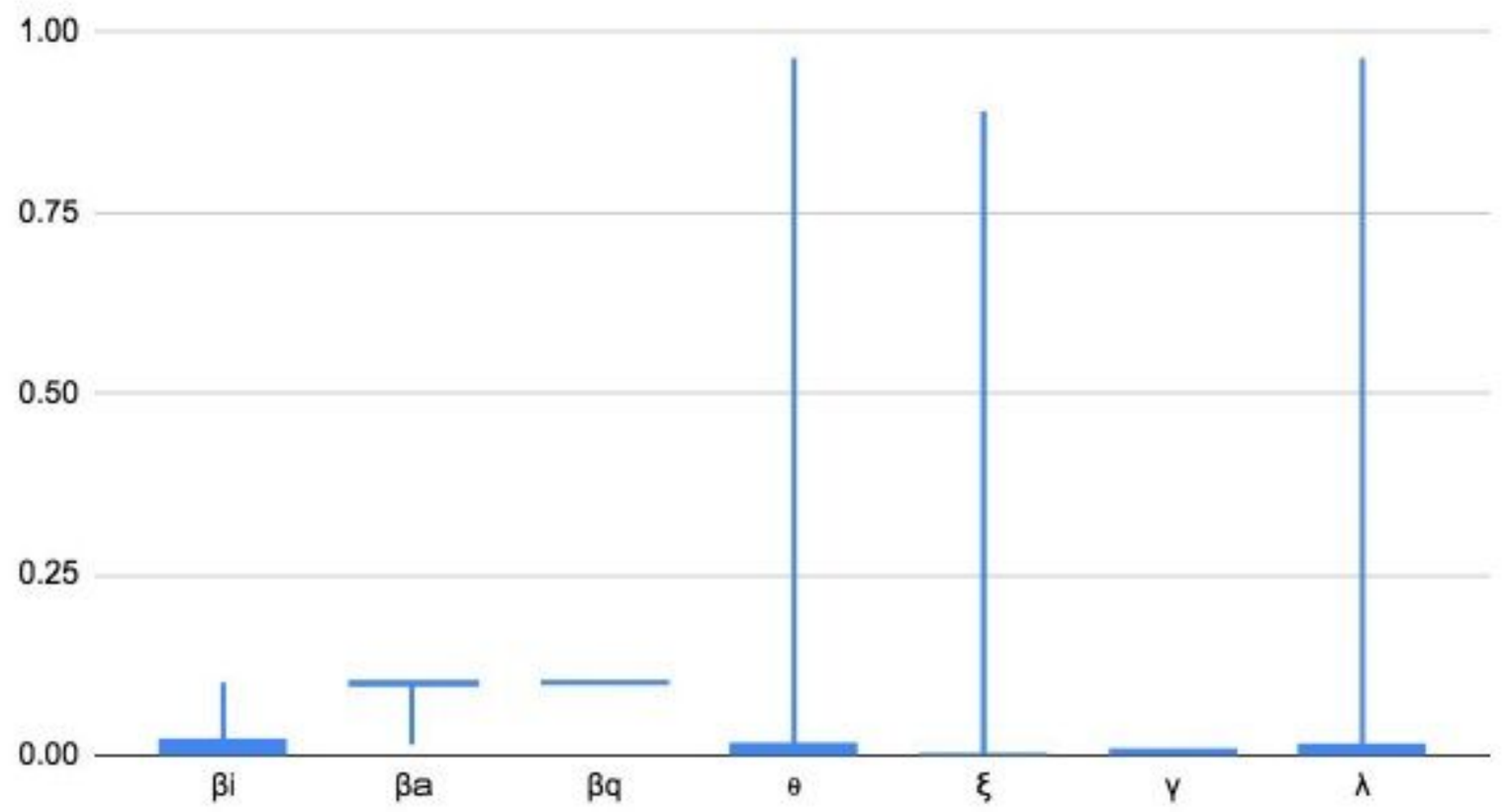

\section{Figure 7}

Infectivity parameter is estimated by LHS PRCC methods based on calculated World population reproduction number $\mathrm{RO}=2.55679495 \% \mathrm{Cl}[2.1189889,2.9945997]$ 


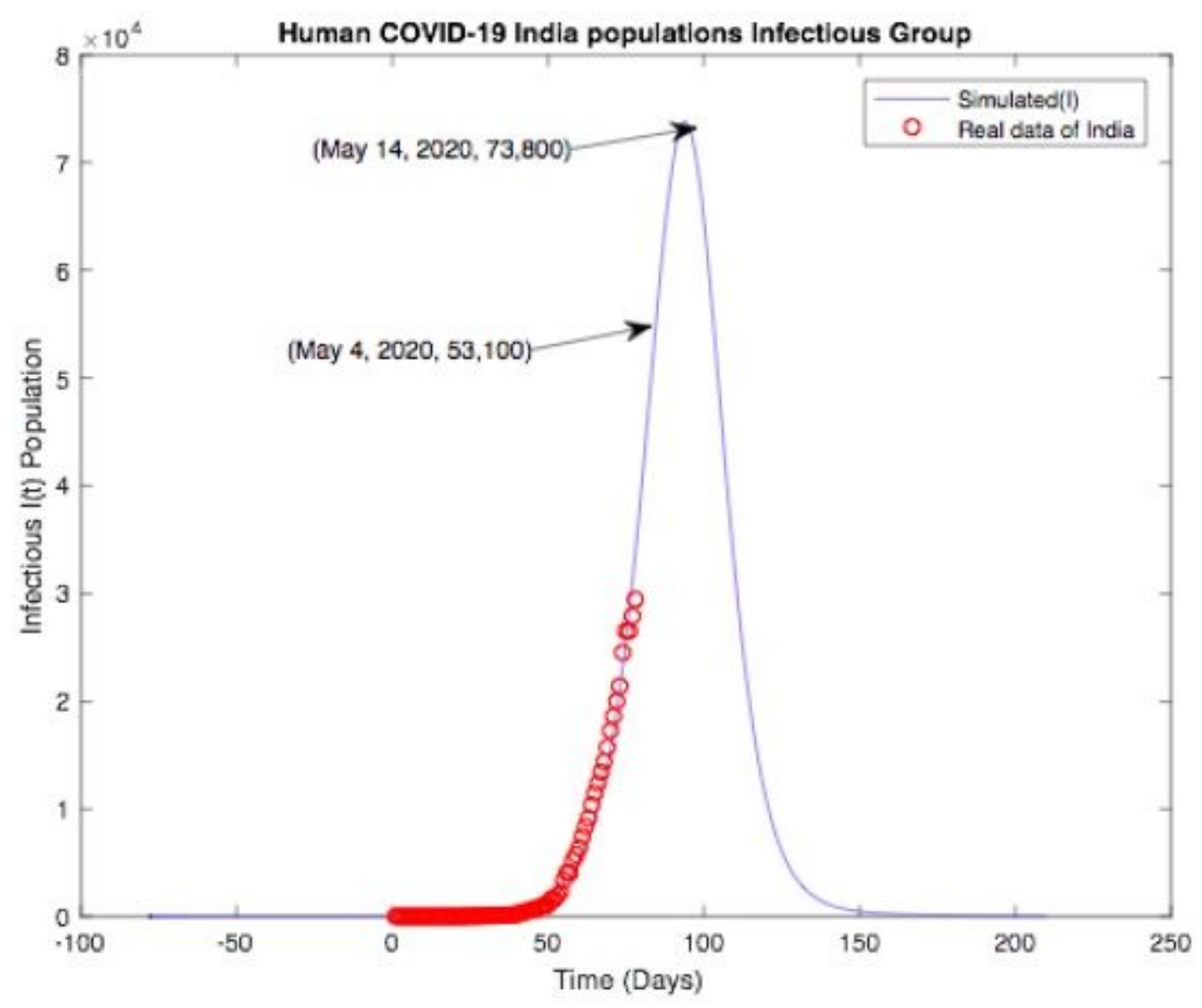

Figure 8

Human COVID-19 India populations Infectious group 


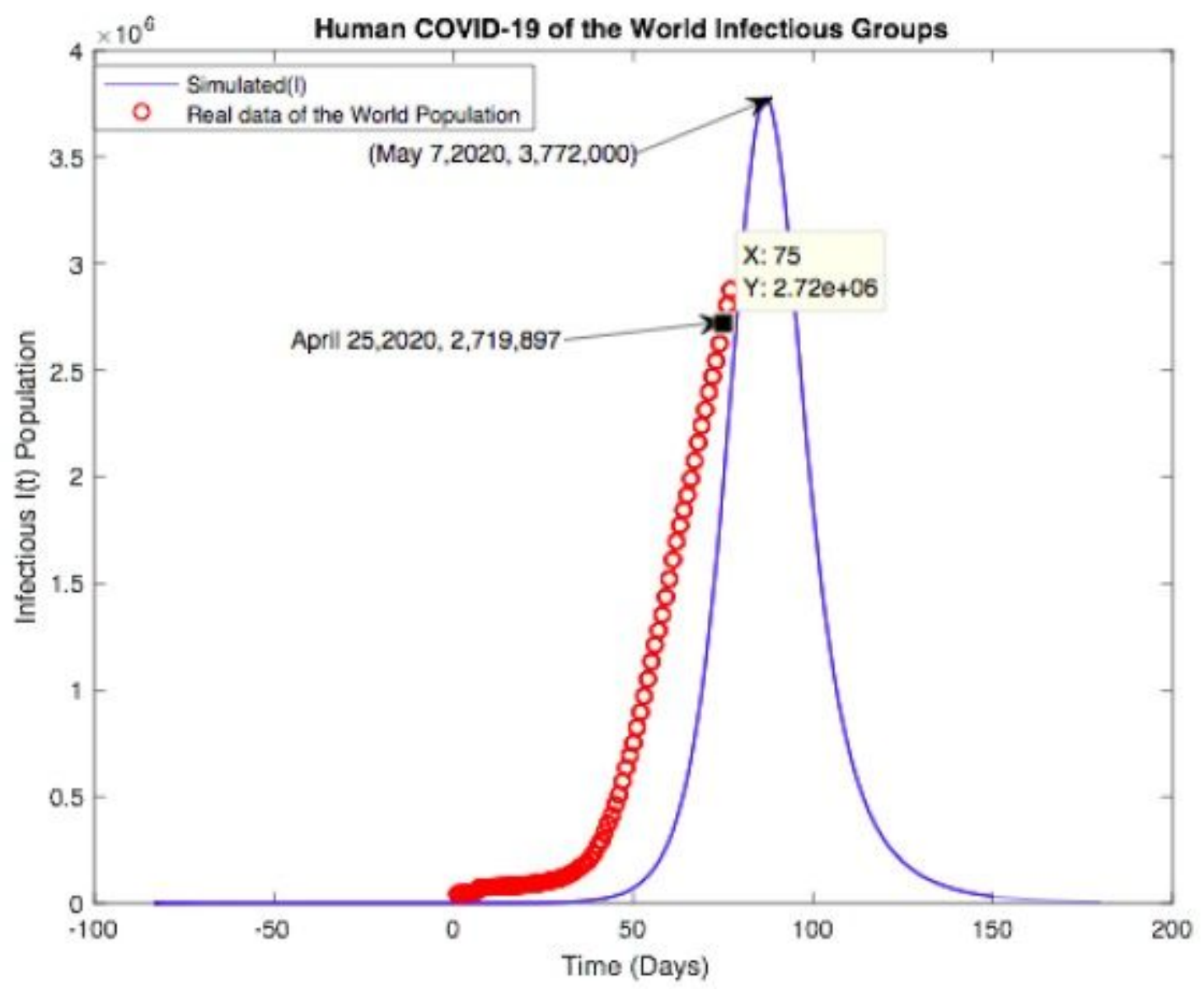

Figure 9

Human COVID-19 of the World Infectious Groups 


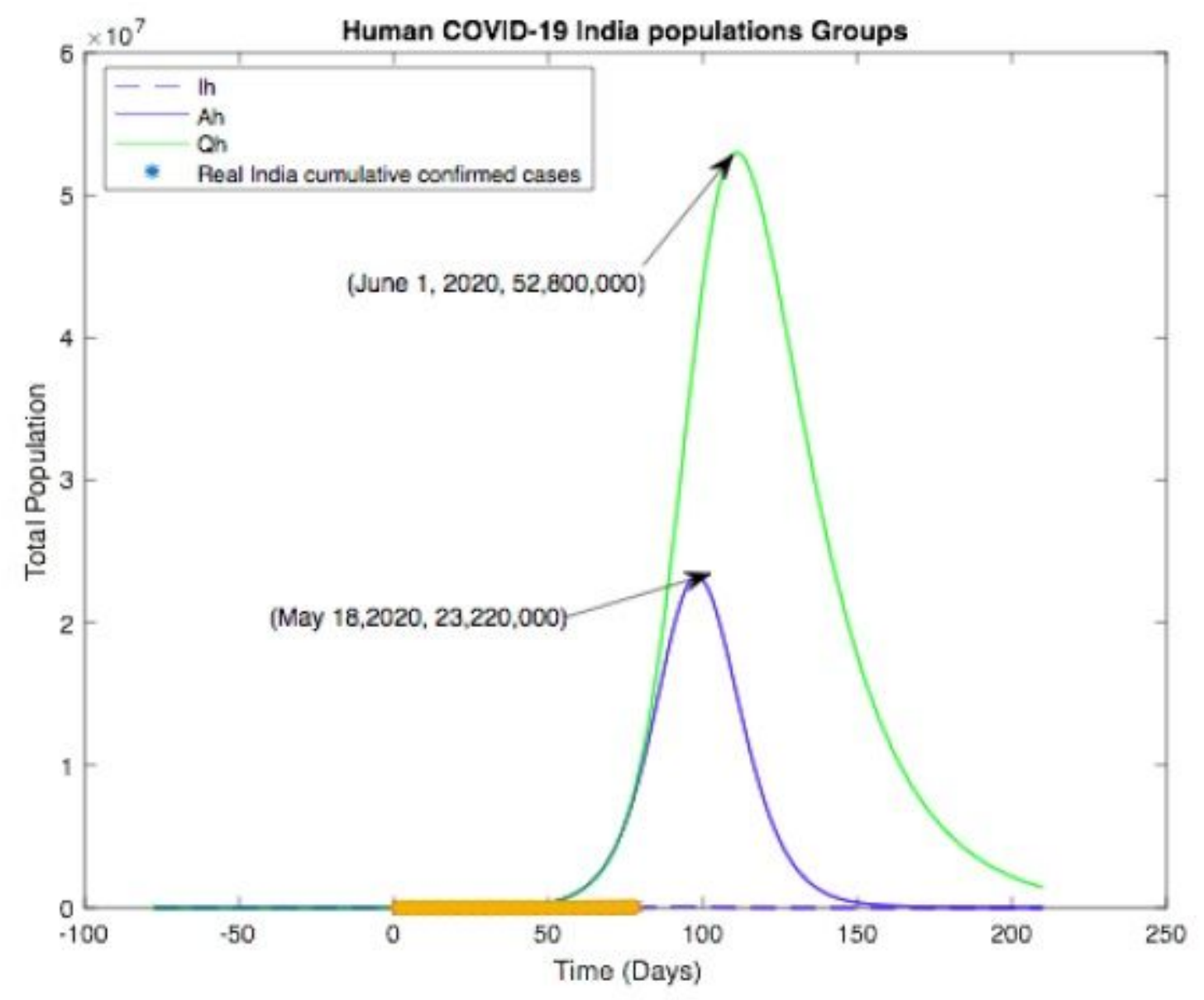

Figure 10

Human COVID-19 India populations Group 


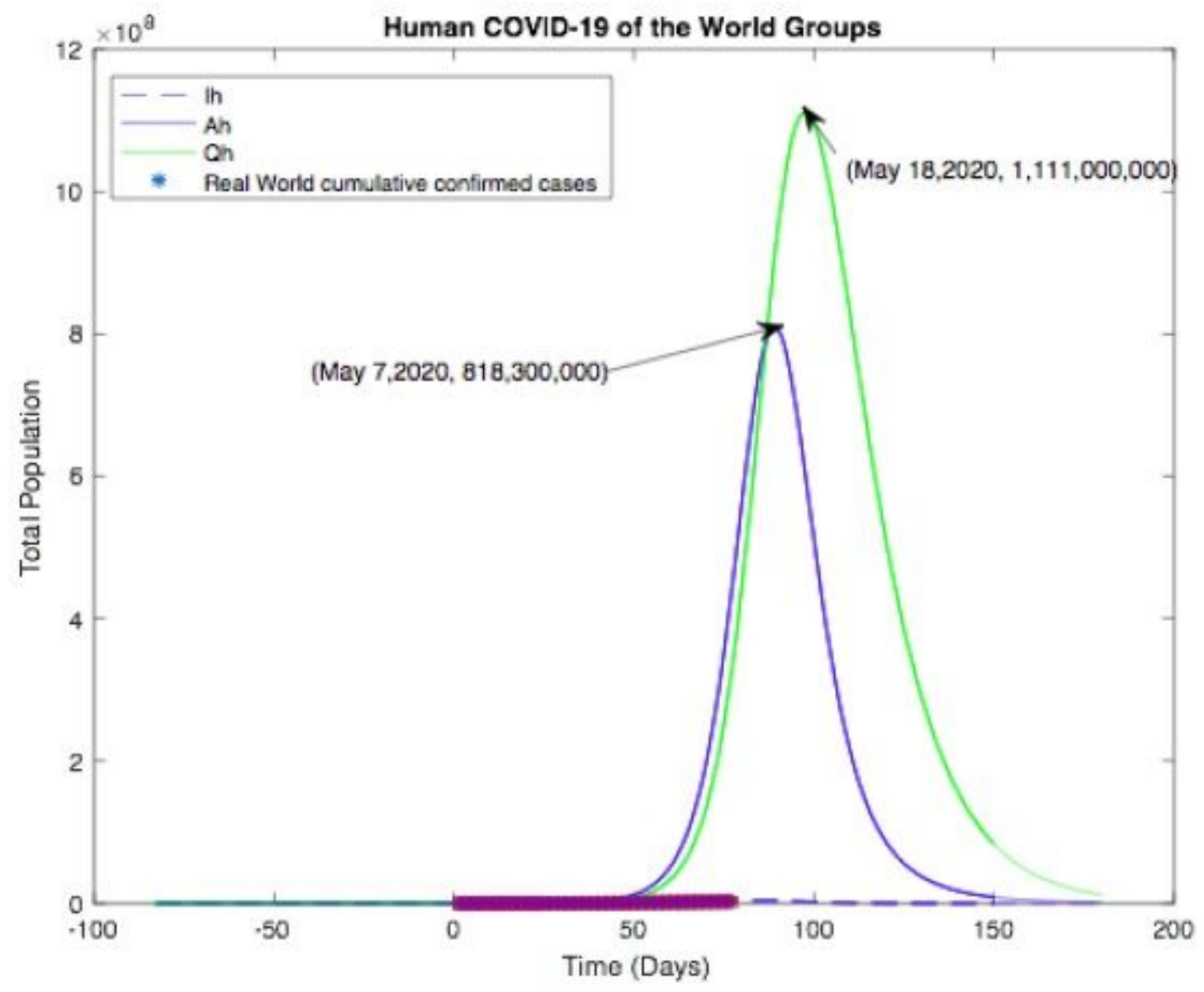

Figure 11

Human COVID-19 of the World Groups 


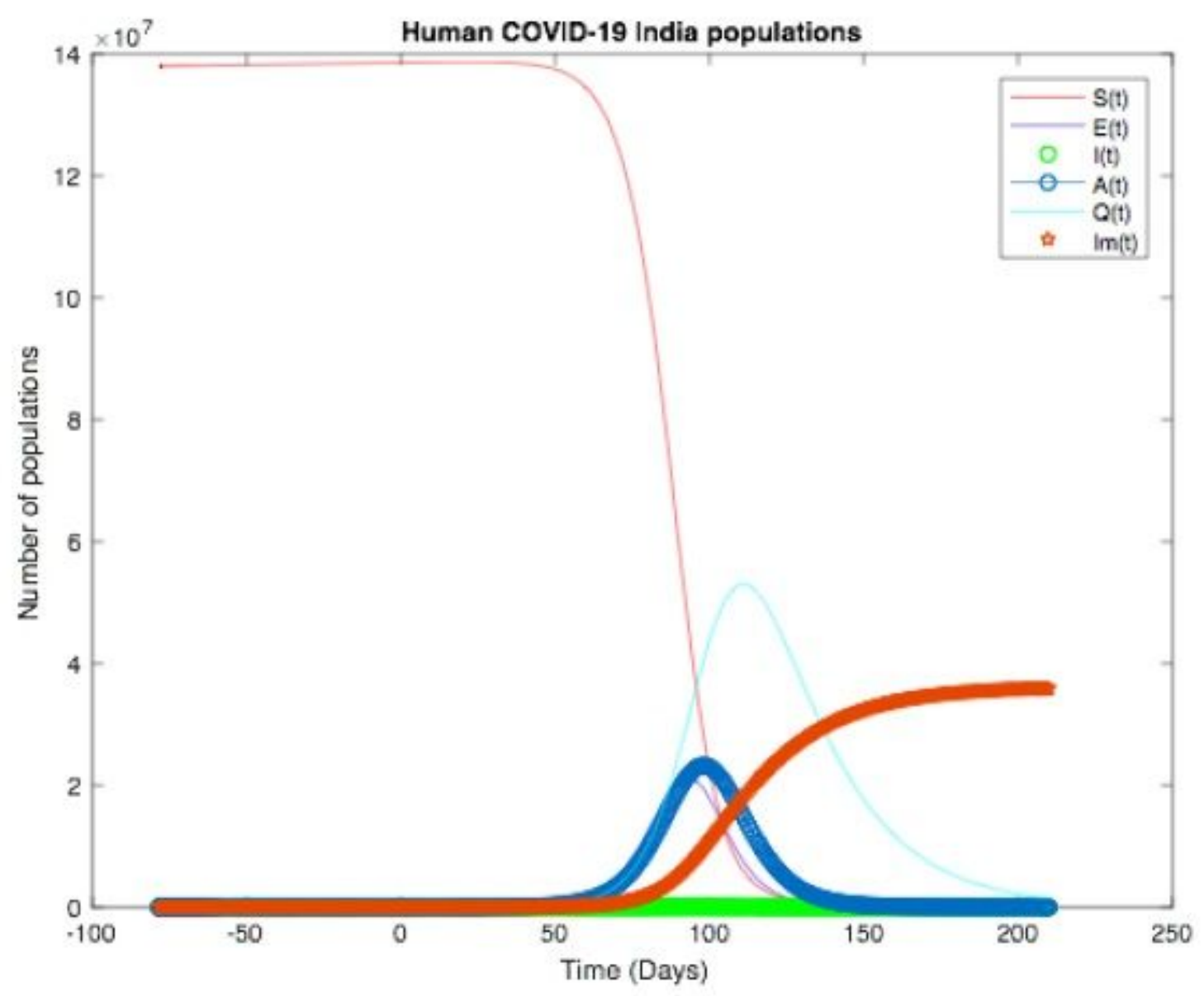

Figure 12

Human COVID-19 India populations 


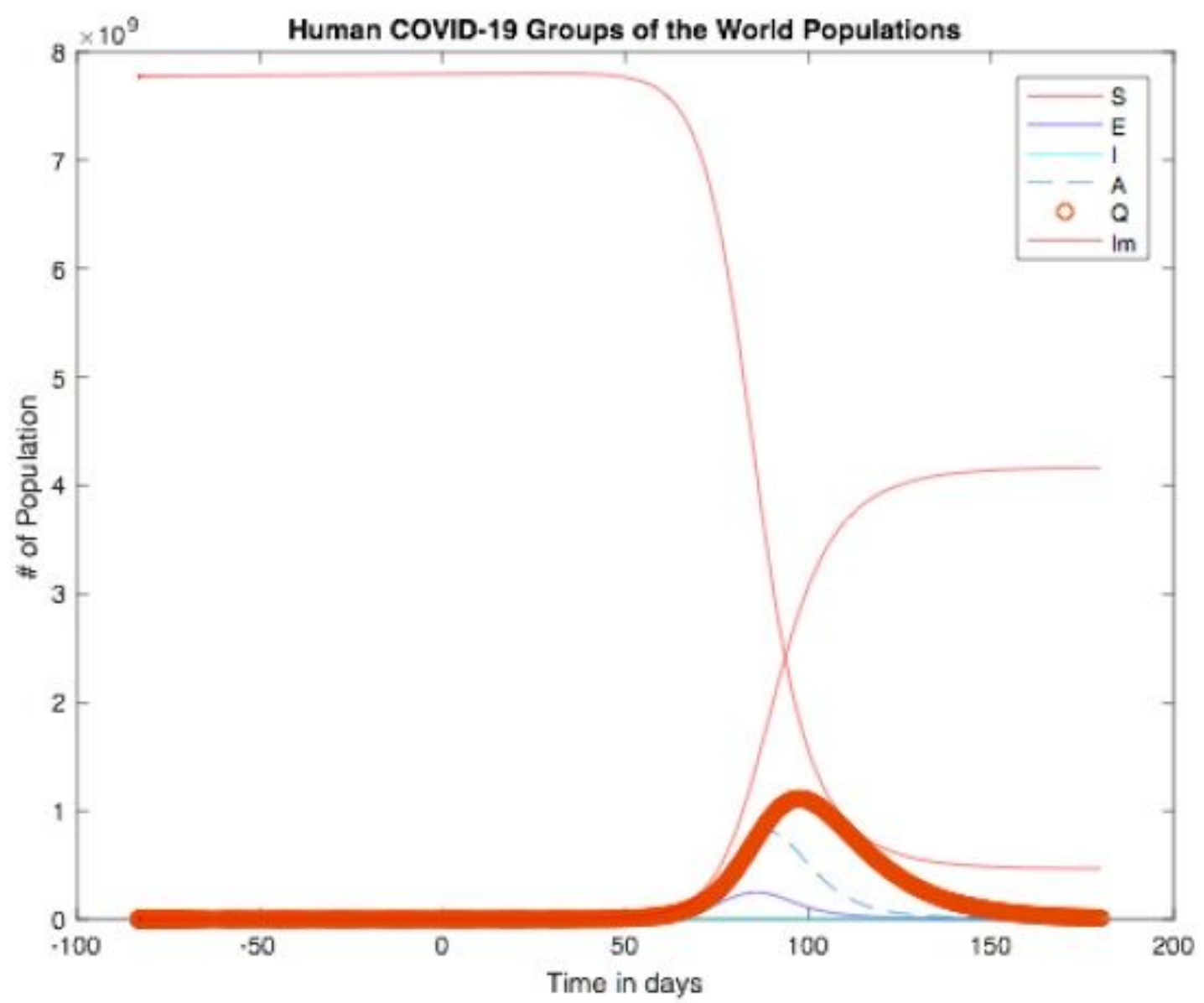

Figure 13

Human COVID-19 Groups of the World Populations 